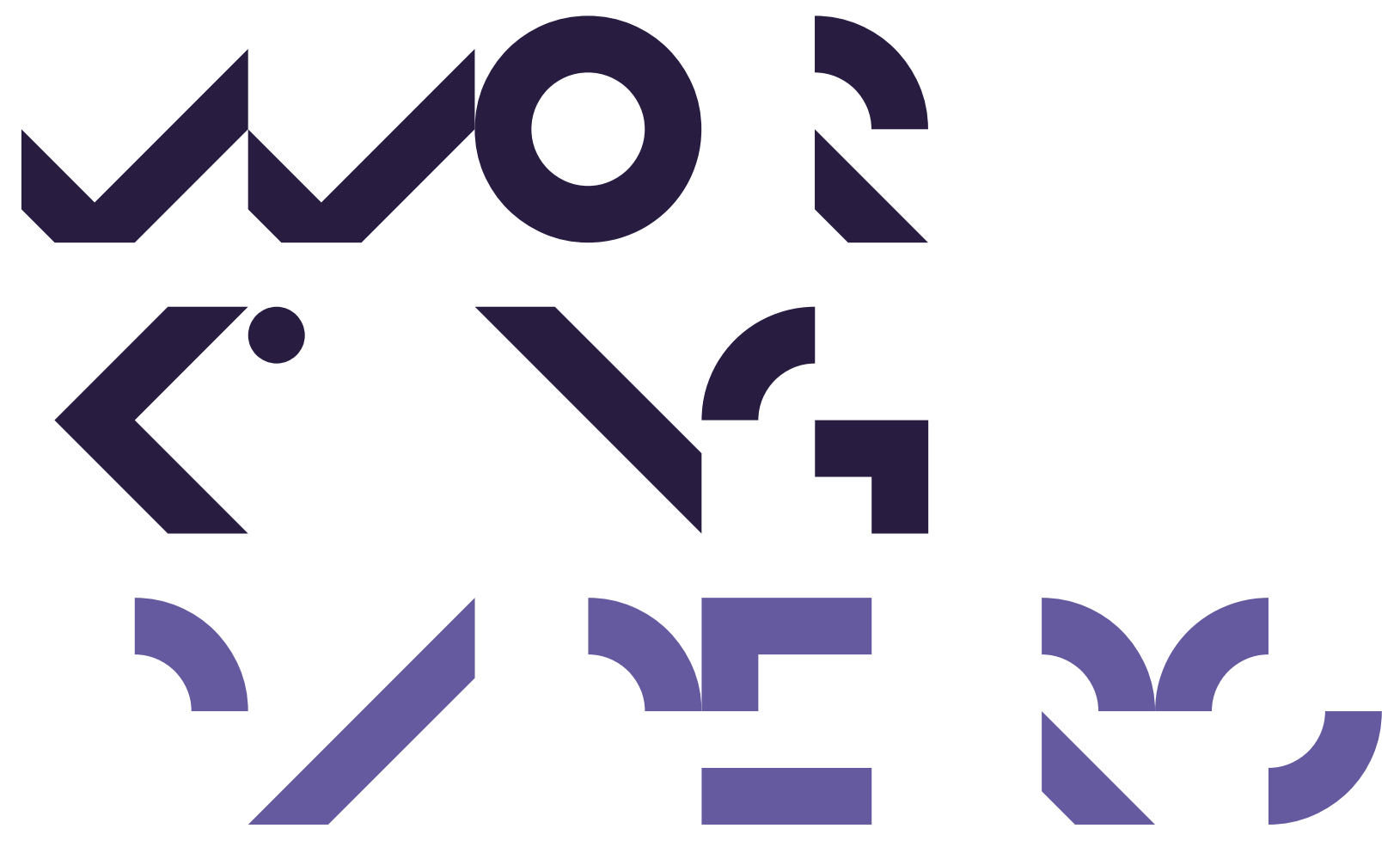

Economics Working Papers

2017-1

How Going to School Affects the Family

Rasmus Landersø, Helena Skyt Nielsen and Marianne Simonsen 


\title{
How Going to School Affects the Family
}

\author{
Rasmus Landersø \\ rl@rff.dk \\ Rockwool Foundation Research Unit
}

\author{
Helena Skyt Nielsen \\ hnielsen@econ.au.dk \\ Aarhus University
}

\author{
Marianne Simonsen \\ msimonsen@econ.au.dk \\ Aarhus University
}

October 2017

\begin{abstract}
:
This paper investigates intra-family spillovers from the timing of school start on outcomes for the entire family. We first document how the timing of a child's school start affects the timing of all subsequent transitions between tiers in the educational system. Exploiting quasi-random variation in school starting age induced by date of birth, we find that the timing of these transitions affect parental outcomes. At child age seven, for example, being one year older at school start increases maternal employment with four percentage points. At child age 15, similarly, being one year older at school start increases the likelihood the parents still cohabit or continue to be married with eight percentage points. Our results also indicate that focal child age at school start improves older siblings' academic performance.
\end{abstract}

JEL: I21, J12.

Keywords: marital capital, marital dissolution, educational transition, regression discontinuity, spillover effects.

Acknowledgements: We appreciate comments from Jon Guryan, Eskil Heinesen, Maria Knoth Humlum, Jan Rose Skaksen, Lars Skipper, and Emma Tominey as well as from seminar participants at the University of Bergen, Lund University, and Paris School of Economics and conference participants at the University of Notre Dame - London Global Gateway Economics of the Family Conference, 2016; the $2^{\text {nd }}$ the Family and Education Workshop 2016; ESPE 2016; and EALE 2016. Financial support from CIRRAU (Simonsen) is gratefully acknowledged. The usual disclaimer applies. 


\section{Introduction}

Education is one of the most important investments in children made by parents and society as a whole. School start is therefore a pivotal point in the life of the individual child, and the consequences of school starting age (henceforth SSA) have been investigated by many researchers. Children perform better in school, both in terms of grades (e.g. Bedard and Dhuey 2006; Cook and Kang 2016; Dhuey et al. 2017) and behavior (e.g. Dee and Sievertsen 2015), when SSA is higher. Yet these shortterm effects do not arise from SSA per se but rather from the persistent age difference between children who start school at different ages. The long-term impact of higher SSA is generally found to be miniscule (e.g. Black, Devereux and Salvanes 2011; Fredriksson and Öckert 2013; Landersø, Nielsen and Simonsen 2017; Dustmann, Puhani and Schönberg 2017).

Children's school start is, however, not only important in terms of their own human capital accumulation; it is also classified as a major stressful life event-a life change unit-both for the children in question as well as for their respective families (Holmes and Rahe 1967). This paper asks whether a policy manipulable variable, such as SSA (and consequently the timing of a child's educational trajectory), has spillover effects to family members other than the targeted child, thereby affecting, for example, family stability and sibling school performance. In other words, when parents actively make changes to when and how they invest in one child given the policy-environment they face, do they - as we would expect from theory - thereby improve the family's outcomes in other dimensions? We will address this key question by estimating the causal effect of SSA on parents' and siblings' outcomes. To the best of our knowledge, we are the first to do this.

Our empirical analysis exploits exogenous variation in SSA generated by administrative rules to circumvent the issue that SSA may correlate with unobservable individual and family characteristics. We make use of the fact that Danish children typically start first grade in the calendar year in which 
they turn seven, which gives rise to a fuzzy regression discontinuity design; a strategy now widely used in the literature on school starting age. By comparing the families of children born in December with families of children born in January, we investigate the effects of focal children starting grade 1 at age 6.6 compared to 7.6. Our analysis uses full population Danish register-based data for focal children born in the period 1986-2000 with information on exact birth dates, family and sibling outcomes, and a rich set of background characteristics.

We show how a child's SSA has direct consequences for their other family members. In the context of this paper, a higher SSA implies that the child spends an extra year in public childcare instead of going to school. ${ }^{1}$ Delaying school start by one year improves parental relationship stability and increases maternal labor market participation while the child is of school age. At child age seven, for example, being one year older at school start increases maternal employment with four percentage points relative to a mean of just below $80 \%$. During child ages $15-18$, being one year older at school start increases the likelihood that the parents continue their relationship with eight percentage points relative to a mean of just above $60 \%$. We observe that, for the most part, the effects for parents' marital stability persist. For maternal employment, however, the effects in the years following school start are different in nature. Here, we instead find a transitory effect around school start, likely because child maturity at school start eases the child's transition from pre-school and into school thereby reducing within-family constraints, which may otherwise have hindered maternal labor supply. ${ }^{2}$

While none of the effects for parental outcomes persists after age 18-20 of the focal child, changes in parental outcomes could still be important in the longer run because they reflect redistribution of

\footnotetext{
${ }^{1}$ This is to a lesser extent true in a US context, although US children have been enrolling in preschool at increasing rates as pointed out by Deming and Dynarski (2008).

${ }^{2}$ Females to a high extent choose careers which allow for such temporal flexibility because they are often secondary workers in the household. Furthermore, their careers are characterized by shorter hours and more career interruptions, which also explains part of the gender wage gap (e.g. Blau and Kahn 2017).
} 
resources within the family to counteract the impact of school start. We indeed find that postponing the school start of one child improves specific dimensions of the academic achievements of older siblings who are close to their final exam around the school start of the focal child. Grades associated with repetitive learning based on memorization (so-called rote learning), such as basic arithmetic and grammar (where parents can teach to the test), improve substantially, whereas grades associated with tasks that are more complex and general knowledge (e.g., essays and text analysis) are unaffected. Hence, delaying the school start of a younger sibling allows parents to redirect resources towards the dimensions in older siblings’ upcoming exams that are most easily improved.

Our results have three important implications. First, they emphasize that educational policies and public investments may have effects beyond their primary objectives and those directly affected by the policy; see, for example, Garces et al. (2002), Joensen and Nielsen (2017), Nicoletti and Rabe (2014), and Qureshi (forthcoming). Not only may the level of public investments in schools make parents adjust their behavior, as found by Cascio and Schanzenbach (2013), Gelber and Isen (2013), and Pop-Eleches and Urquiola (2013). ${ }^{3}$ Our results also show that the timing of public investments matters and shapes parental behavior as well. As such, our paper speaks to the broader family economics literature, including the seminal papers by Becker and Tomes $(1976,1979)$ that are concerned with within-family variation in child outcomes and studies on how parents optimally and under constraints choose to allocate investments across different periods (Cunha and Heckman 2007). Second, our results have bearing for the interpretation of the existing estimates of the consequences of SSA for child outcomes, as the behavioral adjustments of parents and siblings may be some of the mechanisms behind these results. A reallocation of resources to siblings, for example, is likely to dampen the long-run effects of SSA on the focal child. But we also detect a delay in marital disruption, which may or may not improve outcomes of the focal child, depending on the quality of the prolonged

\footnotetext{
${ }^{3}$ Recent work indicates that parents may directly learn from their children; see Kuziemko (2014).
} 
relationship. Finally, our findings illustrate that within-family spillover is not only associated with adverse outcomes in disadvantaged families (Andersen and Wildeman 2014; Garces et al. 2002) or severe child disadvantages, such as ADHD and disability in general (e.g. Black et al. 2017; Breining 2014; Kvist et al. 2013).

To put our results into perspective, Kvist et al. (2013) find that having a child with ADHD impacts relationships earlier on, and increases relationship dissolution already very early in the child's life. At child age one, having a child with a (future) ADHD diagnosis increases relationship dissolution with one percentage point; at child age 10 this estimate has increased to 13 percentage points. The latter should be seen relative to a mean of $30 \%$ in the non-ADHD sample. Effects on maternal employment arise from around child age seven and, in contrast to effects of SSA, seem to persist over time. At child age seven, Kvist et al. (2013) detect a decrease in the likelihood of maternal employment by around 2 percentage points relative to a mean of around $80 \%$.

The paper is structured as follows: Section 2 presents the institutional background and conceptual framework, and Section 3 describes our empirical methodology. Section 4 presents our data and Section 5 presents the results. Finally, Section 6 concludes.

\section{Background}

This section presents three cornerstones to our empirical analysis and findings. We first illustrate how the timing of a child's educational cycle is strongly linked to its age at school start. Second, we introduce the framework linking school start of one child to the family’s lives. And finally, we outline the institutional settings relevant for school starting age in Denmark. 


\subsection{Timing of the education cycle}

Our research design exploits quasi-random shifts in the timing of transitions into school. In any education system with low retention rates, however, there is a strong link between the timing of the transition into school and subsequent transitions in the education system. Figure 1 illustrates the relationship in the context of this paper. The figure shows how, among Danish schoolchildren who enroll in $1^{\text {st }}$ grade during the calendar year when they turn 7 (which is most children), virtually all have left lower secondary school and started upper secondary school during the calendar year when they turn 17. This transition occurs one year later for individuals who started $1^{\text {st }}$ grade during the calendar year when they turned eight and one year earlier for individuals who started $1^{\text {st }}$ grade the calendar year they turned six. Figure 1 illustrates that postponing school start by one year implies postponing graduation by one year and so forth. Hence, a shock to SSA constitutes a shock to the timing of several of the critical school transitions potentially stressing the entire family.

\section{Figure 1}

\section{Enrollment into education by SSA and age}

A) Fraction in primary/lower secondary school (grades 1-10) by age

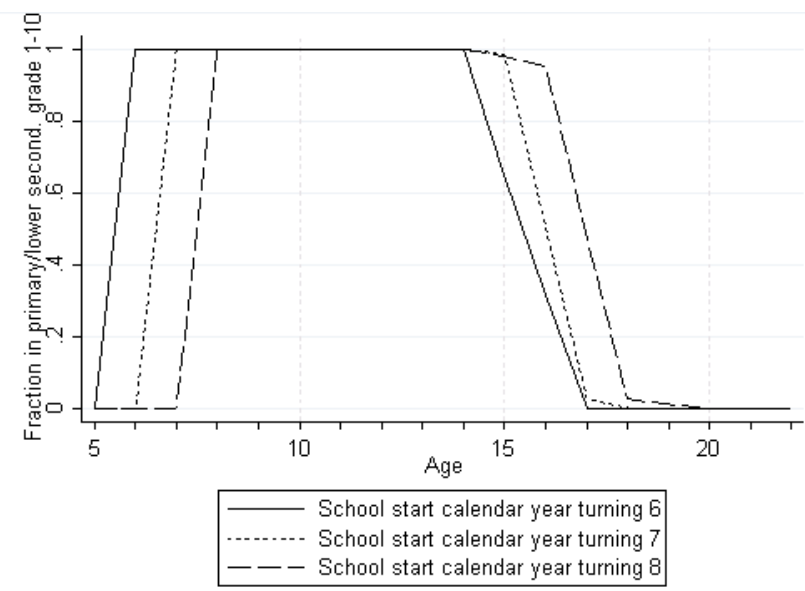

B) Fraction in upper secondary school by age

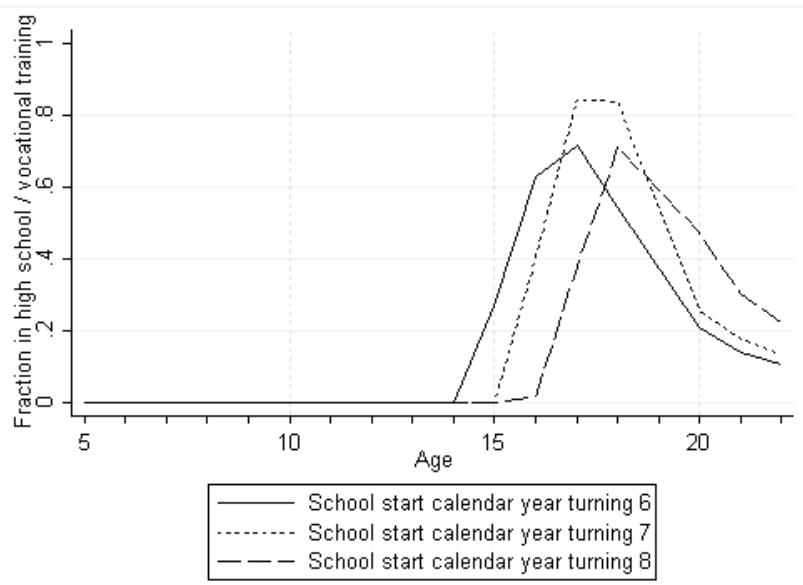

Notes: Figures show the fraction of children born 1986-2000 enrolled in education at each age by whether the child started school the calendar year they turned 6, 7 or 8. Figure A) shows the fraction of children enrolled in primary/lower secondary school, and Figure B) shows the equivalent for enrollment into upper secondary school. 


\subsection{Conceptual framework}

Economists have been concerned with the allocation of parental resources across children since the early work of Becker and Tomes (1976). This topic remains high on the scientific agenda, as seen in the study by Yi, Heckman, Zhang and Conti (2015), who study the reallocation of parental resources in a set-up with multiple skills in families with multiple children.

Given that parents are constrained in terms of resources such as time, money and mental capacity, we expect a shock to one child's trajectory to affect the type, timing and amount of investments parents are able to make in other children in the family. Parents have some flexibility in the allocation of money across various consumption and investment goods, which they can smooth out over time by borrowing and lending. They also have some leeway in the allocation of time between work, leisure and child investments, but the total available time is obviously fixed while mental capacity is fully constrained in that there is limited opportunity to smooth out resources over time.

Our starting point is the observation that the critical transition from childcare to primary school puts additional pressure on parents' resource constraints. Figure 2A shows parents' average daily time spent on childcare per parent during weekdays across a child's age. It is evident that both the time parents spend with their children (the solid line) and time spent reading to/with the child (the dotted line) decrease as children grow up, although with a local maximum around school start at ages 6-7. Figure 2B shows maternal employment patterns by age of the child. Full time work increases with child age with a notable flattening out around school start. We see corresponding high rates of part time work peaking during this period as well, only to decline afterwards.

In conclusion, the figures illustrate that school start is associated with a change in parents' timeallocation (and possibly also their use of mental capacity), in line with, for example, findings from Pop-Eleches and Urquiola (2013) and Fredriksson, Öckert and Oosterbeek (2016). 


\section{Figure 2}

A) Parents' time-use with child, by age of child

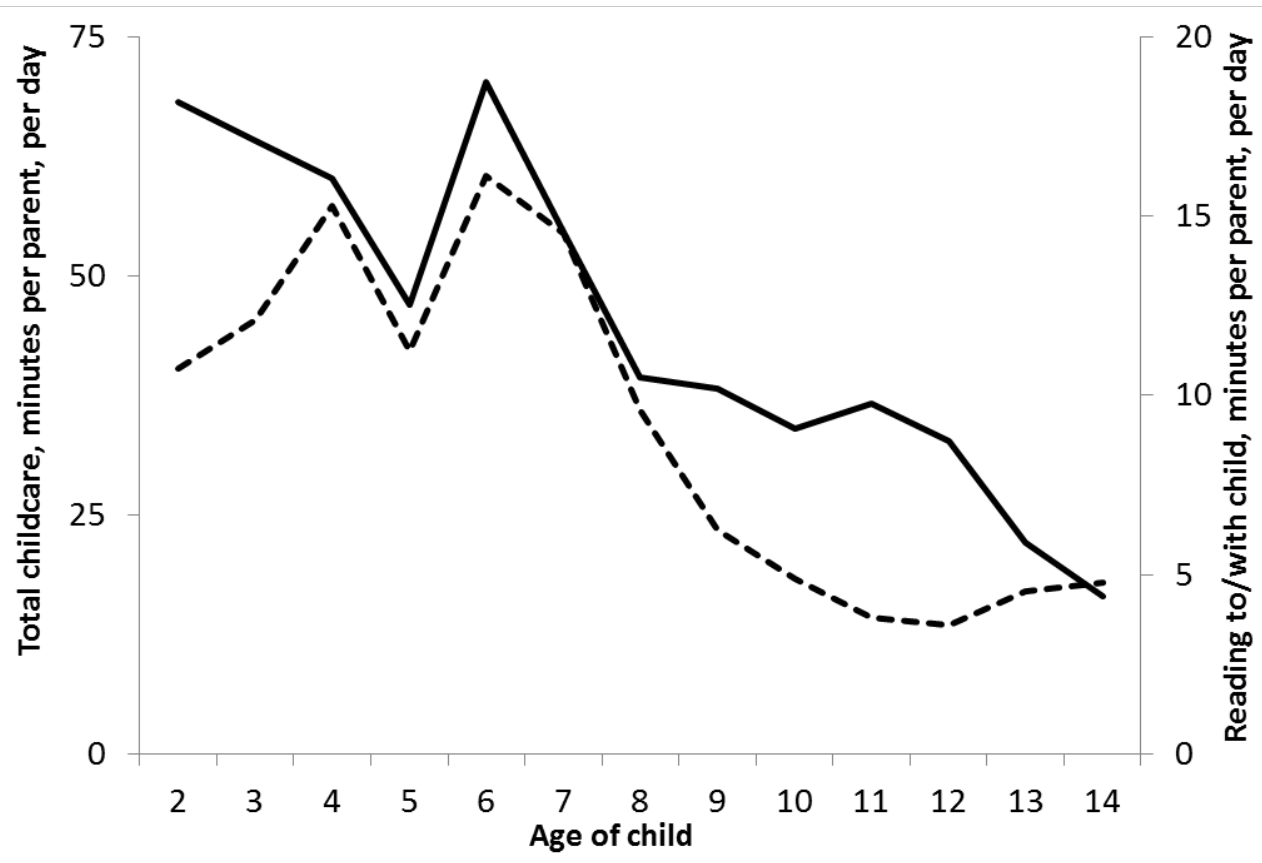

- Time spent on childcare ---Time spent reading to/with child

B) Maternal employment, by age of child

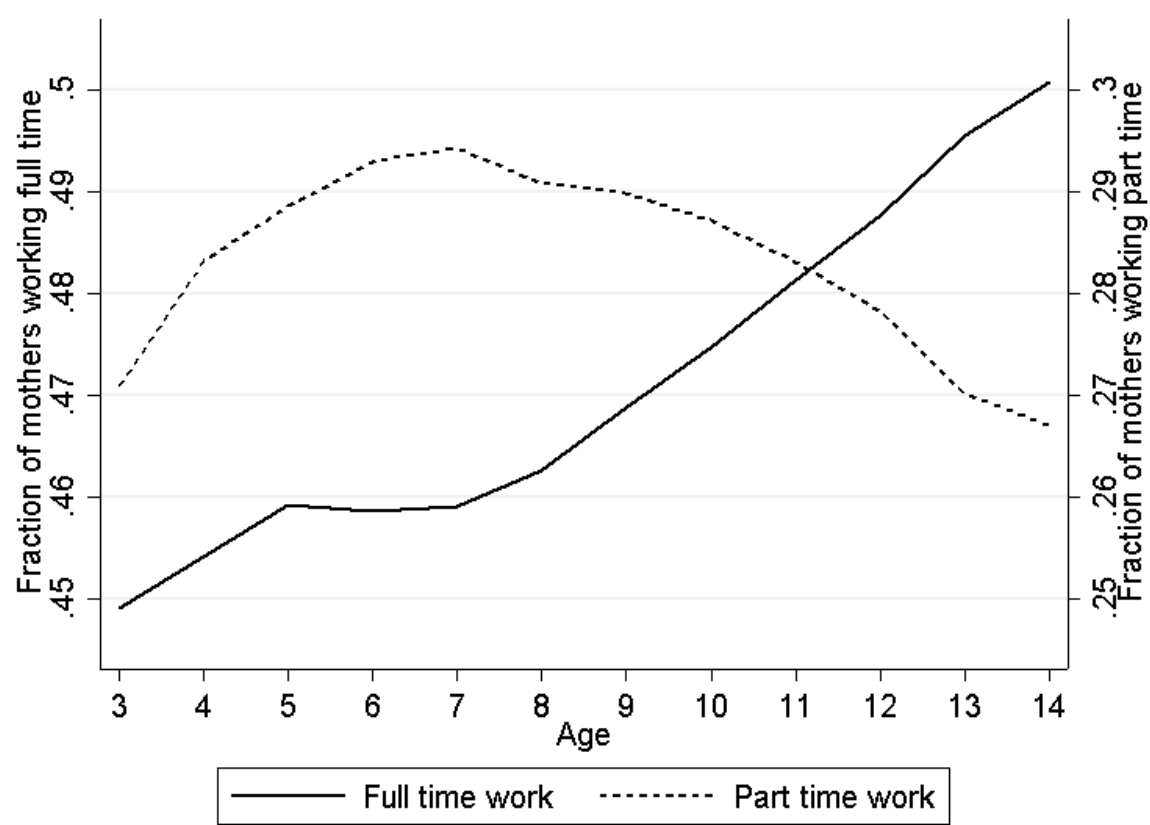

Note: Figure A shows average minutes spent per parent, per day, with the youngest child in the family on care and spare time activities (the solid line), and on reading to/with the child (the dashed line), across the age of the youngest child (own calculations based on DTUC 2008; see Bonke and Fallesen 2010). Figure B shows maternal employment divided by full time and part time work. The figure is constructed using monthly data from October (i.e. right after the start of an academic year) in the years 2008-2010, across children's age. 
Studies that model multi-period resource allocation, such as Cunha and Heckman (2007), illustrate that in a dynamic process, constraints in one period lead to sub-optimal investments in that period relative to other periods in life, possibly producing long-lasting consequences. A very similar intuition applies to our setting: Because families are time-constrained, possibly even facing unanticipated stress due to, for instance, complications in children's critical transitions in the education system, they have limited actions available. Such experiences might therefore have consequences reaching beyond the child in question.

As described above, a change in the distribution of time use and the demands on mental resources may affect the investments that parents are able to make in their other children. More generally, because siblings also interact, such a change may also introduce direct peer effects, just as it may make the parents invest differently in their own relationship. The directions of such effects must be determined through empirical analysis; for example, parents may either reinforce positive events (draw resources away from other siblings) or counteract and redistribute resources to other siblings. Because the existing literature has shown how a higher SSA has immediate consequences for a child's in-school performance and well-being (e.g. Bedard and Dhuey 2006; Dee and Sievertsen 2015), we think of SSA as precisely such a variable and analyze its consequences for the outcomes of all family members. ${ }^{4}$ Moreover, as already mentioned, the existing literature identifies particularly sensitive or stressful periods in the lives of siblings and parents. We therefore investigate if the effects of SSA are particularly pronounced in connection with such key stages (e.g. school start itself and graduation).

\footnotetext{
${ }^{4}$ In principle, parents may respond to a higher SSA already before the actual school start.
} 


\subsection{Institutional settings relevant for school starting age (SSA)}

Our empirical analysis will exploit plausibly exogenous, institutionally induced variation in SSA. This section therefore describes the institutional details influencing school start decisions.

During the period of relevance for this study, Danish law stipulated that education was compulsory from the calendar year of the child's $7^{\text {th }}$ birthday and until completion of $9^{\text {th }}$ grade. ${ }^{5}$ This school system is fortunate for a study like ours because there is no automatic relationship between SSA and minimum required schooling, as is the case in the US and UK systems. Pupils receive teacherassessed grades in grades 8 and 9 and take compulsory exit exams in a number of subjects at the end of grade 9. Further education is voluntary and may follow a more academic path (starting with high school) or a vocational path (vocational school). ${ }^{6}$

The year before entering first grade, children can enroll in kindergarten, ${ }^{7}$ which typically is located in the same building as the school for the early grades (and was voluntary during the period relevant for this study). Kindergarten, compulsory schooling from grades 1-9, upper secondary school and even most higher education programs are free of charge. Furthermore, already at age four, the vast

\footnotetext{
${ }^{5}$ SSA regulations are not strictly enforced and exemptions are granted based on applications from the parents. Exemptions are granted by the local municipality if considered beneficial for the child's development. School start can only be delayed by one year, and school is no longer compulsory from July 31 in the calendar year of the child's $17^{\text {th }}$ birthday, even if $9^{\text {th }}$ grade has not been completed. Schoolchildren do not pass or fail grades; in collaboration with the parents, the school principal can decide that a child repeats or jumps a grade if considered beneficial for the child's development. For more details, consult the Education Act.

${ }^{6}$ It is also possible to complete an elective $10^{\text {th }}$ grade before continuing on an academic or vocational path; opportunity that approximately $50 \%$ of a cohort make use of (e.g., $52 \%$ of the cohort born in 1994 opted for $10^{\text {th }}$ grade).

${ }^{7}$ This is also denoted $0^{\text {th }}$ grade.
} 
majority (98\% in 2004; see statistikbanken.dk) of children are enrolled in some form of public daycare, which is heavily subsidized. ${ }^{8}$

As mentioned above, parents and administrators have considerable leeway when deciding when children should start school. ${ }^{9}$ Therefore, SSA is not random and is most likely affected by a range of factors that may also correlate with the child's outcomes and those of their family. Factors like maturity, school readiness and behavior in childcare may affect the timing of school start.

To address the consequences of SSA, our empirical analysis exploits that the formal age at school start is defined by birth year and employ a strategy similar to Elder (2010), Evans et al. (2010), Black et al. (2011) and Fredriksson and Öckert (2013). January 1 is the relevant cutoff point: according to administrative rules, children born just before this date are supposed to start in school in one year and children born just after in the subsequent year. Some parents of children born close to this cutoff date do choose to manipulate their children's actual SSA: late-year children are more likely to postpone school start by a year, whereas early-year children are more likely to start school one year earlier than stipulated. Consequently, some children born in December will start school one year later than they are "supposed" to—approximately at age 7.6 years_-whereas the remainder of the children born in December will start around age 6.6. Likewise, some children born in January will start school at age 6.6, which is one year earlier than the law stipulates, while the remainder will start school at age 7.6. SSA for children born around the cutoff date is effectively reduced to a binary outcome: children start at age either 6.6 or $7.6 .^{10}$ As described in the beginning of this section, the alternative to starting

\footnotetext{
${ }^{8}$ A minimum of $67 \%$ of the expenses is covered by the local authorities (c.f. the Children's Act).

${ }^{9}$ Documented by Skolestartsudvalget (2006).

${ }^{10}$ Figure A1 illustrates this. The figure shows school starting age pattern across two cohorts by date of birth.
} 
school is to spend an additional year in public daycare. Only a negligible proportion of children are not in daycare immediately before school start.

If children born around the cutoff are 7.6 years old at school start, we label them "old-for-grade.” Figure 3 shows the fraction of children who are old-for-grade by date of birth. There is a smooth upward trend in the fraction of old-for-grade children in December followed by a large discontinuity of approximately 20 percentage points around January 1.

\section{Figure 3}

Fraction - old-for-grade by date of birth

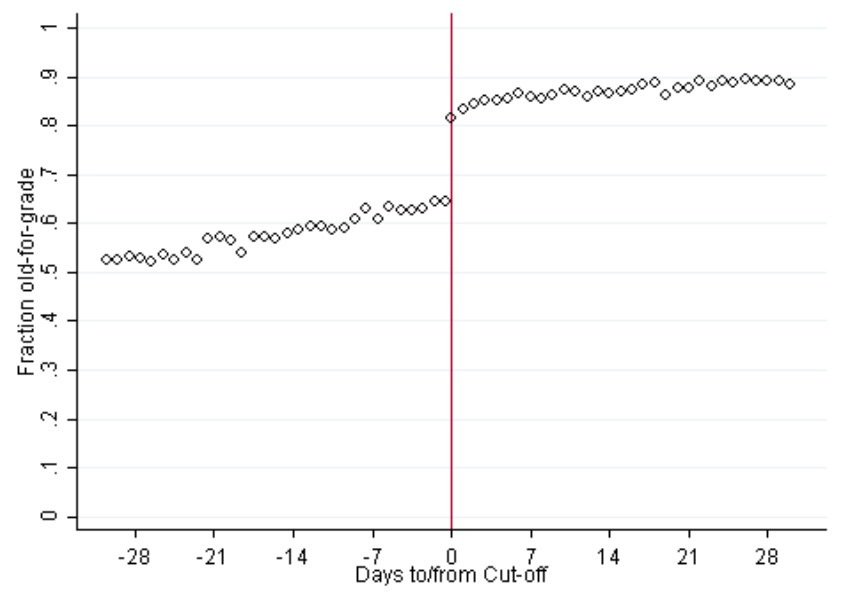

Note: Figure shows the fraction of "old-for-grade" children by date of birth around January 1 (marked by the vertical line). Being old-for-grade implies that the child starts school at age 7.6 instead of 6.6. Averages for population of children born in December or January from December 1986 to January 2000.

\section{Methodology}

Our goal is to estimate the effect of SSA of child $i$ in family $f$ on outcomes of siblings and parents $j$ in the same family. Our equation of interest is the following:

$$
Y_{j f}=\alpha+\beta \cdot S S A_{i f}+X_{i f}^{\prime} \gamma+X_{j f}^{\prime} \delta+\varepsilon_{j f}
$$


where $Y$ denotes the outcome, $X$ observable characteristics ${ }^{11}$ and $\varepsilon$ unobservable characteristics.

In some sense, we can think about administrative SSA rules as affecting the incentives to enroll children later (or earlier) than prescribed by imposing time and effort costs on parents who do not comply with the regime. We can therefore instrument SSA with a dummy for being born immediately after January 1. As argued in the existing literature, such cutoff dates constitute valid instruments in the sense of being uncorrelated with unobserved characteristics of child outcomes. ${ }^{12}$ In order to estimate the local average treatment effect-the average effect of being old-for-grade for the group of children who would be inclined to increase their SSA solely because they were born in January as opposed to December - we also require that the monotonicity assumption is satisfied. Aliprantis (2012), Barua and Lang (2016), and Fiorini and Stevens (2013) argue, however, that monotonicity is likely to be violated if the school starting age distribution of children born just after the cutoff date does not stochastically dominate the corresponding distribution for children born just before the cutoff date. As explained in detail in Landersø, Nielsen and Simonsen (2017), however, monotonicity is likely satisfied in our particular context, where no children start more than one year before/after the date at which they are supposed to start, and SSA in our case is effectively reduced to a binary variable indicating whether the child enrolls at age 6.6 or 7.6; see again Appendix Figure A1.

In practice, we consider a short bandwidth with focal children born \pm 30 days around January 1 . In our main specification, we model SSA as a binary variable indicating a SSA of 7.6 as opposed to 6.6.

\footnotetext{
${ }^{11} X$ includes child and parental characteristics predictive of SSA and outcomes: child gender, an indicator of low birth weight, mother's age at the birth of child, father's age at the birth of child, dummies of number of siblings, whether parents are married measured at age 3 of the child, and whether parents are employed measured at age 3 of the child, and a flexible function of distance in days to the cutoff. In regressions for sibling outcomes, $X$ also includes sibling gender, an indicator of low birth weight of sibling and age distance to focal child.

${ }^{12}$ Our results are unaffected by the finding that children's season of birth is not random (Buckles and Hungerman, 2013), because our identification is based on local exogeneity in the limit around January 1.
} 
We perform standard sensitivity analyses: extended bandwidth around the cutoff, donut RD regression and in- or exclusion of covariates and cohort fixed effects. All conclusions are robust.

\section{Data}

\subsection{Data sources and samples}

We exploit rich administrative Danish data containing information on all individuals residing in Denmark. Our data material provides the following crucial sets of information: 1) family outcomes and sibling school performance, 2) SSA and 3) rich background information. Registers are linked at the personal level via a unique personal identifier. Using parental identifiers, we are able to link children to their parents and siblings. More details about each of these types of information are provided below.

Our starting point is the set of children born from 1986 to 2000. Within this group, for the purposes of our formal analysis, we then select the focal child sample of individuals born around the January 1 cutoff. This sample consists of December-born children in the years 1986-1999 and January-born children from 1987-2000. The parent sample consists of the biological parents of focal children while the sibling sample is made up of siblings born to the same mothers as the focal children. Where two (or more) children from the same family are born around the January 1 cutoff in the observation period, there will be two (or more) focal children observed in the same family ( $7 \%$ of all families in our parent sample are represented more than once because multiple children are born in December or January within our study period). ${ }^{13}$ Our sample initially includes both siblings who are younger and older than the focal children but our empirical analysis will consider older siblings, where the causal link to sibling outcomes is cleaner as older siblings have already started school and cannot be affected

\footnotetext{
${ }^{13}$ We discard all twins from the sample of children born around the cutoff in December and January but not from the sample of siblings.
} 
via changes to their own SSA. The Danish register data spans from 1980-2015, but grades are only available from 2002 and onwards. Therefore, we do not have a complete overlap between the samples used to study all outcomes for focal children, parents and siblings.

Appendix Figure A2 shows the distribution of siblings by age spacing. The histogram illustrates the fraction of siblings for whom we have support for grades for older siblings. The closer siblings are spaced; the relatively more complete is the observation of outcomes in the sibling sample.

In order to ascertain that our results are not driven by skewness in spacing or calendar time in the estimation sample, we perform sensitivity analyses restricting the sample to cohorts where we have complete information about outcomes of all siblings within a maximum age distance of 3, 6 and 9 years, respectively. When we restrict the sample to a maximum of 3, 6 and 9 years age distance, we have complete information about the outcomes of older siblings for focal children born from 1990/91, 1993/94 and 1996/97, respectively, until 1999/2000.

\subsection{Key variables and descriptive statistics}

\section{Measuring school starting age (SSA)}

We do not observe the exact timing of SSA for the cohorts under analysis. Instead, we use age in $8^{\text {th }}$ grade (minus eight) as an approximation. This works because the vast majority (90\%) of old-forgrade children at the end of elementary school are already old-for-grade in kindergarten, whereas very few children are delayed from grade 1 onwards. ${ }^{14}$

\section{Outcome variables}

\footnotetext{
${ }^{14}$ In practice this implies that we observe the treatment variable with measurement error. This will not affect results as long as the instrumental variable (the cutoff) is unrelated to this error. Landersø, Nielsen and Simonsen (2017) validate our approach by exploiting more recent data with information about exact SSA to show that the measurement error does not vary across the cutoff.
} 
We consider the effects of the focal child's SSA on a range of family outcomes: parents' relationship stability (measured by an indicator variable for whether parents are married/cohabiting measured on January 1 every year following school start), parental employment (measured by an indicator variable for whether parents are employed or not in November each year following school start), and mothers' wage earnings from the income registers which are based on tax information. We also consider the impact on older siblings' academic performance in terms of exit exam results after grade 9.

To get a sense of the development in parents' relationship stability over time, Figure 4A illustrates the proportion of parents cohabiting or married at a given focal child age. When the focal child is 3 years old, around $85 \%$ of parents live together, while the number is down to $60 \%$ when the child turns 20. Figure 4B shows the development in parental employment: Around $87 \%$ of fathers and $72 \%$ of mothers are employed when the child is 3 years old. As the focal child grows older, the maternal employment rate approaches the paternal rate. As a result of the average age difference between mothers and fathers, parents' labor market trajectories intersect when the focal child reaches their teens. Paternal employment rates decline during the children's teens, while maternal employment rates start increasing before they also start to decline.

Table 1 shows the distribution of older siblings' grades. The Danish grading scale is numerical and corresponds directly to the reported ECTS scale. The modal grade is C, and 33\% have grades lower than $\mathrm{C}$ in math while around $40 \%$ have grades lower than $\mathrm{C}$ in some of the Danish disciplines. In the empirical analysis, we standardize grades to have mean 0 and standard deviation 1 based on the numerical scale.

One concern that might change the interpretation of our results throughout the paper is if the focal child's SSA is related to the subsequent birth of siblings (i.e. fertility). We have studied this relationship, which could introduce additional shocks to parents' investments and time-use. The 
results are shown in Table A2. We find that subsequent fertility is not significantly related to the focal child's SSA, which supports our interpretation of the results presented; see Section 6.

Table 1: Distribution of older siblings' exit exam grades (grade 9)

\begin{tabular}{llcccc}
\hline Grades & & Math & Danish (Written) & Danish (Grammar) & Danish (Oral) \\
\hline 12 & A & 0.082 & 0.047 & 0.051 & 0.155 \\
10 & B & 0.203 & 0.153 & 0.132 & 0.193 \\
7 & C & 0.387 & 0.405 & 0.404 & 0.337 \\
04 & D & 0.177 & 0.254 & 0.225 & 0.184 \\
02 & E & 0.100 & 0.119 & 0.139 & 0.103 \\
00 & Fx & 0.051 & 0.022 & 0.049 & 0.029 \\
-3 & F & 0.000 & 0.001 & 0.000 & 0.000 \\
\hline \multicolumn{2}{l}{ Observations } & 50,086 & 50,086 & 50,086 & 50,086 \\
\hline
\end{tabular}

Note: Table shows the distribution of older siblings' exit exam grades at the end of grade 9. The table is based on the population of children born from 1986 to 2000. 


\section{Figure 4: Parents' outcomes by focal child's age}

A) Fraction of parents cohabiting or married

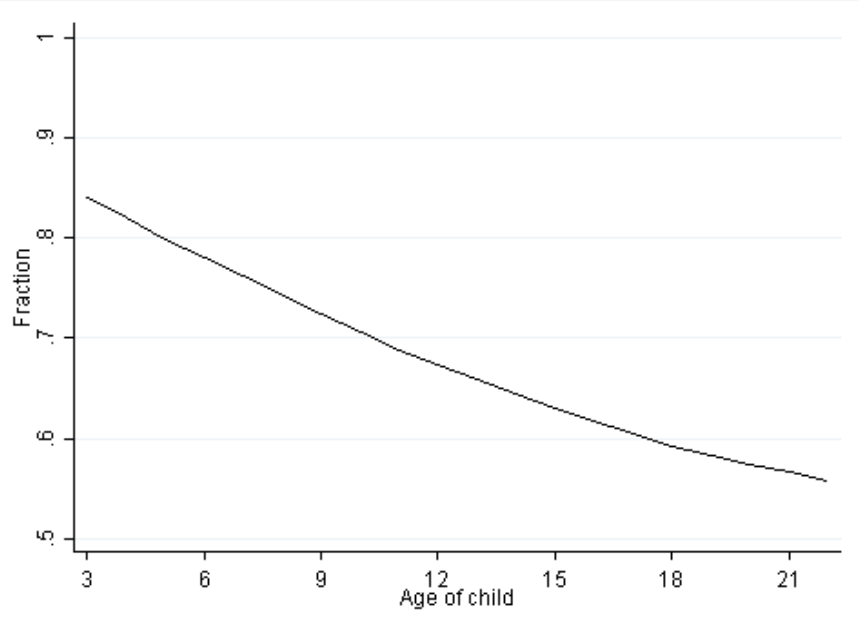

B) Parental employment by focal child's age

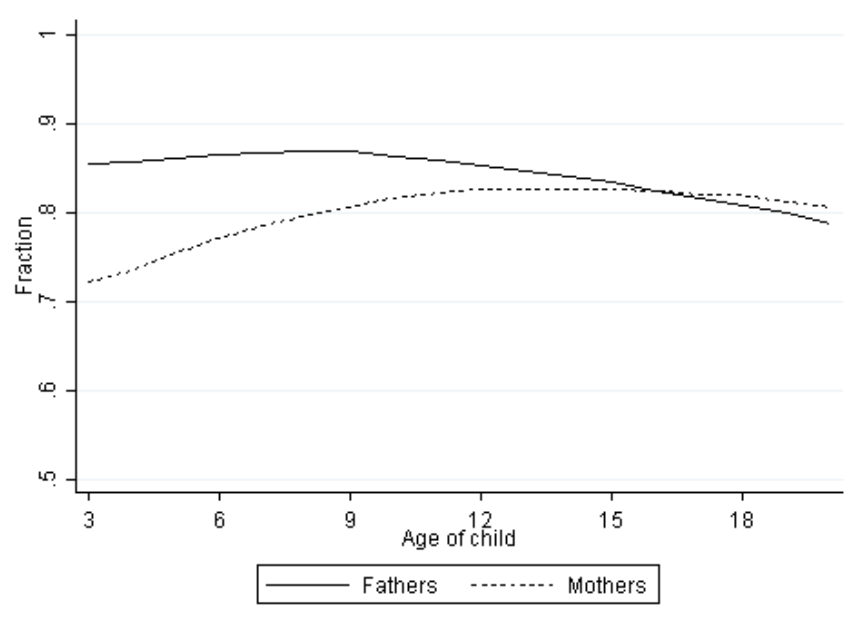

Note: Figure A) shows the fraction of parents cohabiting at a given age of the focal child. The figure is based on the population of children born from 1986 to 2000. Figure B) shows the fraction of parents working in November, by age of the focal child. The figure is based on the population of children born from 1986 to 2000.

\section{Background characteristics}

Using the registers, we combine information on the children's birth weight, demographic variables and educational variables by the unique individual identification number. We also link these data to 
information about parents' characteristics as measured one year prior to and three years after the birth of the child. Descriptive statistics for the background characteristics are reported in Table A1 in Appendix A.

Importantly, we center all covariates and outcome variables on the cutoff dates instead of by calendar year. Hence, we compare background information on children born in January year t to the information on children born in December year t-1 instead of comparing information on children born in January year t to the information on children born in December year t. ${ }^{15}$ Table 2 shows joint Ftests from a regression of the instrument on the rich set of background variables for children born \pm 30 days around January 1 . These tests clearly suggest that the sample is balanced across the cutoff. ${ }^{16}$ Also, columns 3 and 4, where we include parents' characteristics as measured when their child is 5 years old, show that there is no response to children's timing of birth before their supposed school start. In the subsequent analyses the set of covariates consists of the variables included in column 2.

Table 2: Balancing test

\begin{tabular}{lcccc}
\hline & $(1)$ & $(2)$ & $(3)$ & $(4)$ \\
\hline F-statistic & 1.00 & 0.84 & 0.90 & 0.78 \\
p-value & 0.43 & 0.55 & 0.50 & 0.60 \\
\hline Observations & 132,039 & 132,039 & 132,039 & 132,039 \\
\hline Distance to cutoff & $\mathrm{X}$ & $\mathrm{X}$ & $\mathrm{X}$ & $\mathrm{X}$ \\
Child characteristics at birth & $\mathrm{X}$ & $\mathrm{X}$ & $\mathrm{X}$ & $\mathrm{X}$ \\
Parental characteristics, child age 3 & $\mathrm{X}$ & $\mathrm{X}$ & $\mathrm{X}$ & $\mathrm{X}$ \\
Cohort fixed effects & & $\mathrm{X}$ & & $\mathrm{X}$ \\
Additional parental characteristics, child age 5 & & & $\mathrm{X}$ & $\mathrm{X}$ \\
\hline
\end{tabular}

Note: Table shows F-statistics and associated p-values from OLS regressions. Columns 1 and 2 show results of a regression of birth month (January $=1$ ) on distance to cutoff (in days), background characteristics of focal child and parents (as presented in Table A1) and cohort fixed effects, whereas columns 3 and 4 show results when additional parental characteristics at age 5 are added (marriage /cohabitation and maternal employment).

\footnotetext{
${ }^{15}$ For children born in December 1986 or January 1987, we use parental characteristics measured in 1985, whereas for children born in December 1987 or January 1988 we use parental characteristics measured in 1986 etc.

${ }^{16}$ We have plotted the variation of selected control variables on either side of the cutoff and find no significant differences across the cutoff for any of the control variables, which further strengthens the credibility of the empirical approach.
} 
Table A1 also shows the average characteristics of the compliers (those who are old-for-grade as a result of the administrative January 1 cutoff and thus those for whom the first stage is stronger), estimated as described in e.g., Almond and Doyle (2011). The table illustrates how the average family size of compliers differs from the average family size of the remaining sample. Compliers are more likely to be girls and have more siblings. The latter indicates that the complier families in question may be particularly sensitive to shocks to time use and mental resources and more likely to be constrained in these aspects. There is a weak tendency for compliers to be positively selected in terms of other characteristics. ${ }^{17}$

\section{Results}

\subsection{Timing of birth within the calendar year and school starting age}

Table 3 presents the results from the first stage regression using an indicator variable for birth in January as instrument for SSA. The table shows the first stage results estimated both with and without background variables. Note that the coefficient estimate associated with the instrument does not change with the inclusion of other control variables. All specifications include cohort fixed effects (indicator variables for being born Dec 1986-Jan 1987, Dec 1987-Jan 1988 etc.) and the distance in days to the cutoff linearly. Being born in January rather than December increases the likelihood of child school start at age 7.6 instead of at 6.6 years with 20 percentage points.

\footnotetext{
17 This is different from the US context (see Deming and Dynarski, 2008).
} 
Table 3: First stage results

\begin{tabular}{lll}
\hline & \multicolumn{1}{c}{$(1)$} & \multicolumn{1}{c}{$(2)$} \\
\hline January (0/1) & $0.201^{* * *}$ & $0.201^{* * *}$ \\
Distance to cut-off, January & $(0.005)$ & $(0.004)$ \\
& $0.002^{* * *}$ & $0.002^{* * *}$ \\
Distance to cut-off, December & $(0.000)$ & $(0.000)$ \\
& $-0.004^{* * *}$ & $-0.004^{* * *}$ \\
Birth weight<2000g & $(0.000)$ & $(0.000)$ \\
& & $0.157^{* * *}$ \\
Boy & & $(0.015)$ \\
& & $0.178^{* * *}$ \\
Boy*Birthweight<2000g & & $(0.002)$ \\
& & $-0.079^{* * *}$ \\
Older siblings & & $(0.021)$ \\
Parents married/cohab., at age 3 & & $-0.012^{* * *}$ \\
& & $(0.003)$ \\
Mother's age at birth & & -0.005 \\
Father's age at birth & & $(0.003)$ \\
Constant & & -0.000 \\
& & $(0.000)$ \\
Observations & & $-0.002^{* * *}$ \\
F squared & & $(0.000)$ \\
\hline
\end{tabular}

Note: Table shows results from linear regressions of indicators for starting school at age 7.6 instead of 6.6 for children born in December or January while conditioning on the cutoff dummy (January = 1), distance to cutoff, cohort fixed effects and background characteristics. Standard errors in parentheses $+\mathrm{p}<0.10,{ }^{*} \mathrm{p}<0.05,{ }^{* *} \mathrm{p}<0.01,{ }^{* * *} \mathrm{p}<0.001$.

\subsection{Effects on parents}

This section investigates parents' own responses to the timing of their child's school start. For each outcome we present three sets of results. First, we show the usual 2SLS estimates across children's age. Second, to accompany and deepen our understanding of the 2SLS results, we estimate compliers' potential outcomes if children were young-for-grade or old-for-grade, in line with Abadie (2002, 
2003). If, on the one hand, the potential outcomes diverge exactly around the critical stages but are aligned otherwise, effects likely arise due to an easier transition between different educational stages. If, on the other hand, potential outcomes are parallel across ages, this supports a hypothesis that effects stem from a simple intertemporal response to the postponement of the child's life-course including all critical transitions, by one year. Lastly, we combine the 2SLS analysis with a reestimation of the effects of being old-for-grade on parents' relationship status and maternal employment rates where we align the outcomes by grade level instead of age. If results arise from parallel changes to parents' trajectories as a consequence of the delayed life-course, the estimated effects for outcomes centered by grade level should be miniscule, whereas if our findings arise because postponing children's SSA actually eases the transition, effects should persist around the timing of the transitions, even when we center outcomes by grade level.

Figure 5A shows the estimated effects of being old-for-grade on the probability that parents live together (married or cohabiting) at a given age. Until age 6, the point estimates are small and not significantly different from zero. In some sense, we can think of this as a placebo test (or a test of foresight) as children have yet to start school. From the child turns 7 and onwards, the family is more likely intact if the focal child is old-for-grade than young-for-grade, although the estimates are only borderline significant at a $10 \%$ level. The old-for-grade children are in kindergarten at this exact January 1 cutoff, whereas young-for-grade children are in grade 1 . The coefficient estimates jump again around the focal child's $15^{\text {th }}$ birthday. At this point in time, children who are old-for-grade are in the middle of $8^{\text {th }}$ grade while the young-for-grade children are in the middle of grade 9 and approach the lower secondary exit exam taking place 6 months later in June. Appendix Figure A3 shows the corresponding reduced form scatterplot at child age 15. A further investigation shows that children who are the youngest among their siblings drive this effect, which suggests that parents postpone split-up until the youngest child has graduated; results are available upon request. The significant 
effects of being old-for-grade on parents' relationship status are, however, not persistent in the longer run. They peak when the child is aged 15-17 and approach zero afterwards.

Figure 5B presents the counterfactual outcomes in the old-for-grade and young-for-grade states of those who are old-for-grade if they were born on January $1^{\text {st }}$ and not on December $31^{\text {st }}$. The vertical distance between the two lines correspond to the estimates plotted in Figure 5A. Figure 5B shows a smooth reduction in parental marital/cohabitation rates if the child is young-for-grade $\left(\mathrm{Y}_{0}\right)$. If the child is old-for-grade $\left(\mathrm{Y}_{1}\right)$, parents would follow the same trajectory until school start, where parental marital/cohabitation rates stagnate for one year. From age 7 until 14, parents' marital/cohabitation rates follow parallel trends, regardless of SSA. At 14, marital/cohabitation rates of old-for-grade parents stagnate, while they decline for young-for-grade parents. This is followed by a gradual convergence between the two counterfactual outcomes until the child is 21 years old. Consequently, in Figure 5C, the estimated effects from daycare until grade 8, when we align parents' relationship status by grade level, are insignificant and close to zero, suggesting that any initial response on parents' relationship stability is a result of the focal child's postponed life-course. From grades 1012, however, significant effects of being old-for-grade on the parents' marital/cohabitation rates emerge. These are exactly the years when the child finishes compulsory schooling and enrolls in upper secondary school, suggesting that the transitions into primary school and later into upper secondary school do not impact family resources similarly. 
Figure 5: Fraction married or cohabiting

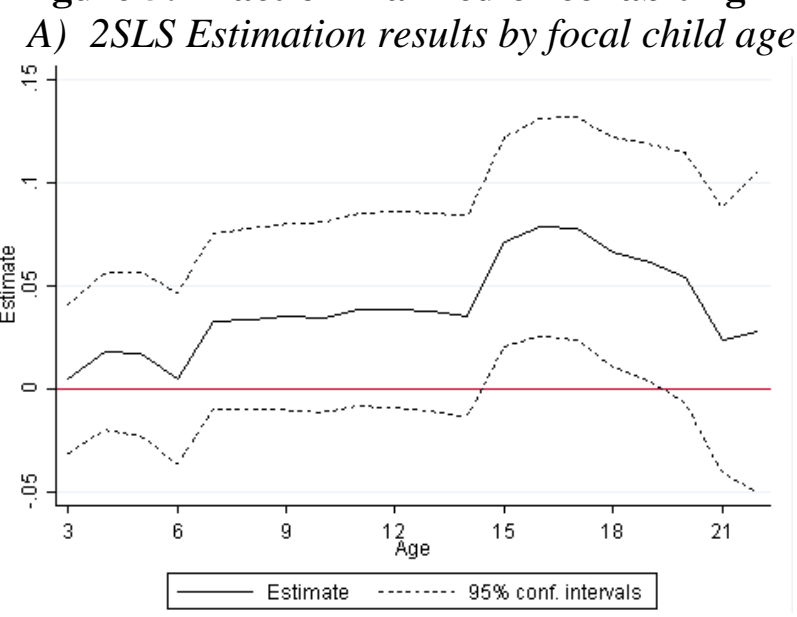

B) Compliers' counterfactual outcomes by focal child age

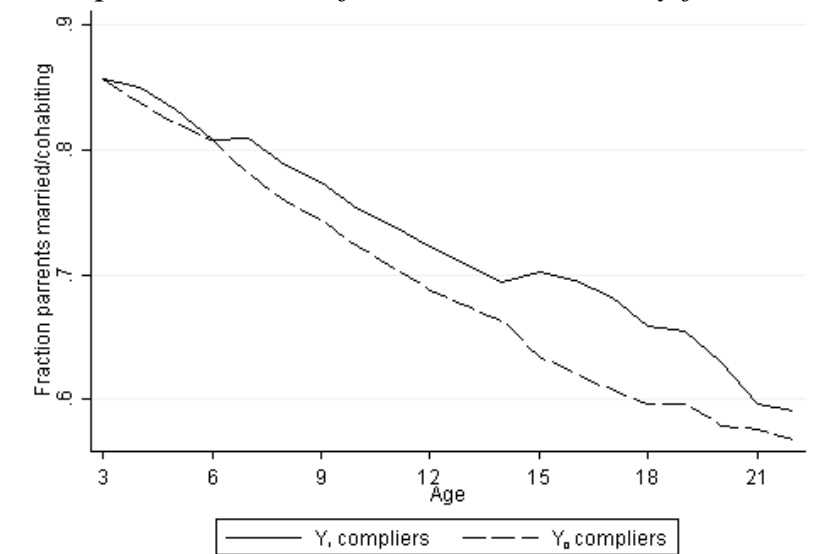

C) 2SLS Estimation results by focal child's grade level

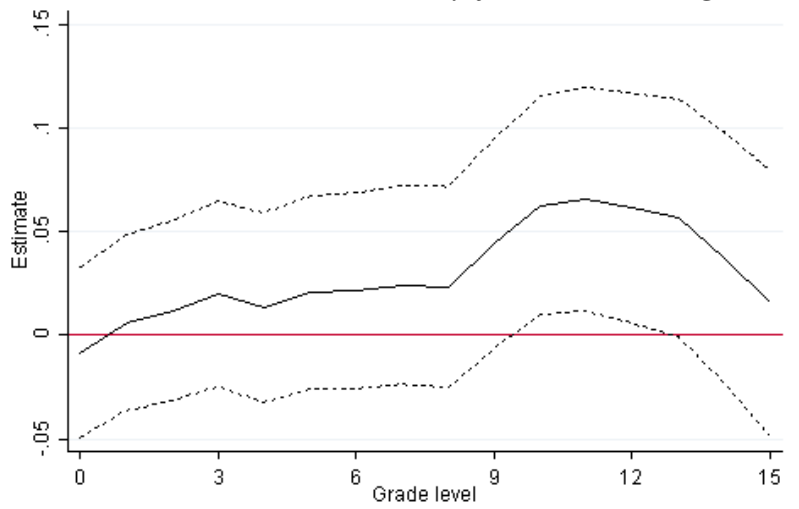

- Estimate -.-.-... 95\% conf. intervals

Note: Figure A) shows the estimated effects of being old-for-grade on parents' relationship status across child's age from age 3-22 and Figure C) shows estimates across grade level from grade 0-15 based on 2SLS regressions of fraction of parents who are married or cohabiting at a given age/grade. Cutoff dummy (January =1) used as instrument. Conditioning set includes distance to cutoff, cohort fixed effects and background characteristics (see Table A1). Dashed lines indicate 95\% confidence intervals. Figure B) shows the compliers' estimated counterfactual outcomes as in Abadie (2002) where the vertical distance between the two counterfactual outcomes corresponds to the points estimates shown in Figure A). Tables A3 and A4 show the estimates presented visually in Figures 5A and C. 
Figure 6 shows the estimated effects of a child's SSA on maternal employment. Mothers work more often when the focal child is age 7 if school start is later. At age 7, young-for-grade children have started first grade while old-for-grade children are still in kindergarten. Note that there are no significant effects on employment before age seven. Estimates are still positive once both treated and untreated children have started school (age eight and onwards) but become statistically insignificant. ${ }^{18}$ Appendix Figure A4 shows the corresponding reduced form at child age 7. Of course, as shown in Figure 4B, around $75 \%$ of mothers are already working when the child is aged 7 . We therefore expect effects on employment to be driven by mothers with relatively low socio-economic status. We explore this in our heterogeneity analyses below. We find no effects of a child's SSA on paternal employment (not shown) as paternal employment rates are high and stable across focal child age (see Figure 4B). These results suggest that maternal labor supply is hindered by constraints within the family; constraints, which are removed in the short run by postponing school start. ${ }^{19}$

When we focus on how the counterfactual employment rates diverge at age 7, Figure 6B shows employment rates for mothers who have old-for-grade children are consistently above those for mothers who have young-for-grade children until the child turns 17, the largest differences being in the early schooling years. Hence, a later school start allows parents to allocate more resources to themselves and parents (mothers) respond to the decision of delayed school start immediately after the decision has been put into effect. This is confirmed by Figure 6C, which shows that being oldfor-grade results in significant positive effects. During grades 1-3, maternal employment rates increase by 4-6 percentage points (5-7\% relative to the $\mathrm{Y}_{0}$ ) if their child is old-for-grade.

\footnotetext{
${ }^{18}$ Results are robust to extending bandwidth to \pm 45 days instead of \pm 30 days around New Year; see Figures A5 and A6.

19 This is in line with Blau and Kahn (2017) who find that the temporal flexibility of women in terms of career interruptions and shorter hours play an important role for the gender gap. This suggests that women react to constraints within the household by adjusting their labor market activity.
} 


\section{Figure 6: Maternal employment}

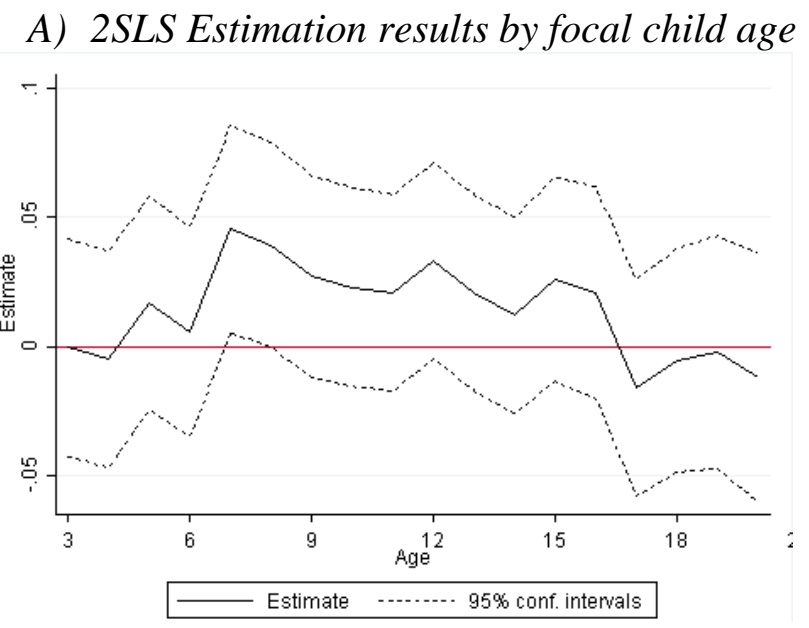

B) Compliers' counterfactual outcomes by focal child age

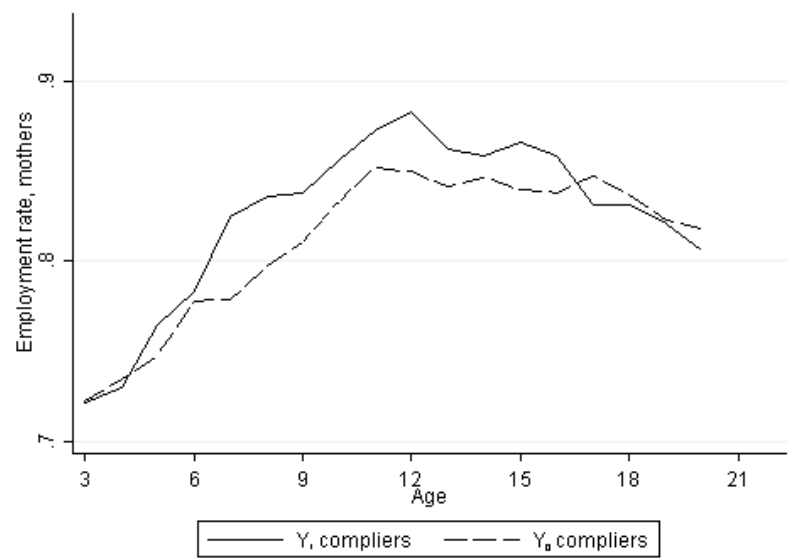

C) 2SLS Estimation results by focal child's grade level

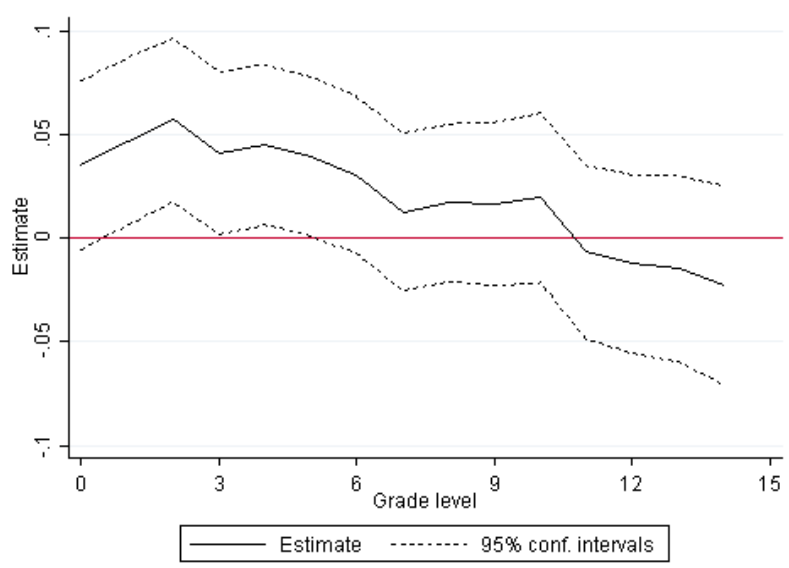

Note: Figure A) shows the estimated effects of being old-for-grade on maternal employment across child's age from age 3-22 and Figure C) shows estimates across grade level from grade 0-15 based on 2SLS regressions of fraction of mothers in employment at a given age/grade. Cutoff dummy (January = 1) used as instrument. Conditioning set includes distance to cutoff, cohort fixed effects and background characteristics (see Table A1). Dashed lines indicate 95\% confidence intervals. Figure B) shows the compliers' estimated counterfactual outcomes as in Abadie (2002) where the vertical distance between the two counterfactual outcomes corresponds to the points estimates shown in Figure A). Tables A3 and A4 show the estimates presented visually in Figures 6A and C. 


\subsection{Margins of response}

Mothers' labor supply responses beg two new questions: Are there intensive margin adjustments for mothers who already hold a job? And do mothers take up part-time or full time jobs?

As a first step, Appendix Figure A7.A shows the effects of being old-for-grade on mother's place in the earnings distribution of all mothers in Denmark by focal child's age. The figure mimics the findings from Figure 6A and show a borderline significant effect around school start at ages 7-9 with average income percentiles increasing by 2-3 percentage points if the child is old-for-grade instead of young-for-grade. Furthermore, Appendix Figure A7.B illustrates the margin of response. Mothers are more likely to move away from the bottom quartile of earnings if their child is old-for-grade.

In Figure 7 we investigate these effects in greater detail by showing how being old-for-grade affects the earnings distribution of mothers in our sample at ages 7, 8, and 9. To do so we create a series of dummies indicating whether a given individual's wage earnings fall below a given level $w_{i f}=$ $1\left[\right.$ wage earning $\left._{i f} \leq x\right]$. We then vary $x$ from 0 to the maximum observed earnings in our sample and estimate a separate regression using each of the individual dummies $w_{i f}$ as outcomes. The estimated effects of being old-for-grade will thereby show how the cumulated earnings distribution is affected at a given level of $x$. Figures 7A, C, and E show the counterfactual cumulated earnings distributions for compliers at age 7, 8, and 9. Figures 7B, D, and F show the corresponding 2SLS estimates of the effects of being old-for-grade on the cumulative distribution of mothers' earnings, which corresponds to the vertical distance between the lines in Figures A, C, and E. Extensive margin effects will be the vertical differences between the lines and the corresponding 2SLS estimates at \$0. Intensive margin effects implies mass being shifted upwards in the earnings distributions at positive levels of earnings. This will be manifested as ranges where the vertical distances between the lines in Figures A, C, and E grow and the point estimates in Figures B, D, and F decrease. 
From Figure 7 we see that a substantial change has taken place at the extensive margin. As found in Figure 6, extensive margin effects at ages 7 and 8 are on average roughly 4-5 percentage points and only 2 percentage points at age 9. Figure 7, however, also shows substantial underlying intensive margin effects. There are around 5\% fewer mothers earning below \$20,000 per year (which corresponds to part-time work), even at age 9 which showed no statistically significant extensive margin effect. From the figure we see that these mothers have been shifted from wage earnings in the range between $\$ 1-20,000$ to wage earnings between $\$ 20-40,000$ which are the ranges where the solid and dashed lines in Figures A, C, and E converge and the point estimates in B, D, and E moves towards zero. When we investigate the degree to which our findings differ with parental education, Appendix Figure A8 shows that point estimates of the effect of SSA on labor supply (and marriage patterns) are larger among low educated mothers than seen in Figure 6A (and 5A). ${ }^{20}$ Together, these results not only illustrate that a substantial fraction of mothers increase labor supply and enter employment as a result of families being relieved of time and mental constraints the when a child's school start is postponed, but also that this benefits mothers who already hold a job and can increase labor supply at the intensive margin and move to full-time employment. ${ }^{21}$ These transitions also correspond closely to the average maternal employment patterns across children's age shown in Figure 2B which shows that prevalence of part-time employment peaks when the child is 6 while levels of full time employment stagnate only to resume the upward trends from 8-9 and onwards.

\footnotetext{
${ }^{20}$ Of course, the group of compliers may vary with maternal education, which complicates direct comparisons.

${ }^{21}$ Full time employment at the average minimum wage between sectors correspond to an annual income of approximately $\$ 25,000$. As we see effect mainly for low skilled mothers, the shift from wage earnings between $\$ 1$ 20,000 to $\$ 20-40,000$ thus correspond to a shift from part-time to full time employment.
} 
Figure 7: Effects of being old-for-grade on mother's wage earnings at child age 7, 8, and 9

A) Counterfactual cumulated wage earnings distribution, age 7

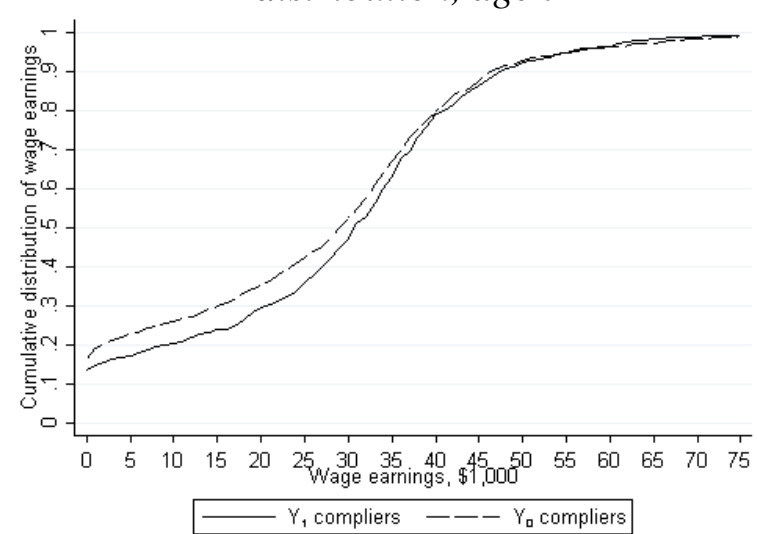

C) Counterfactual cumulated wage earnings distribution, age 8

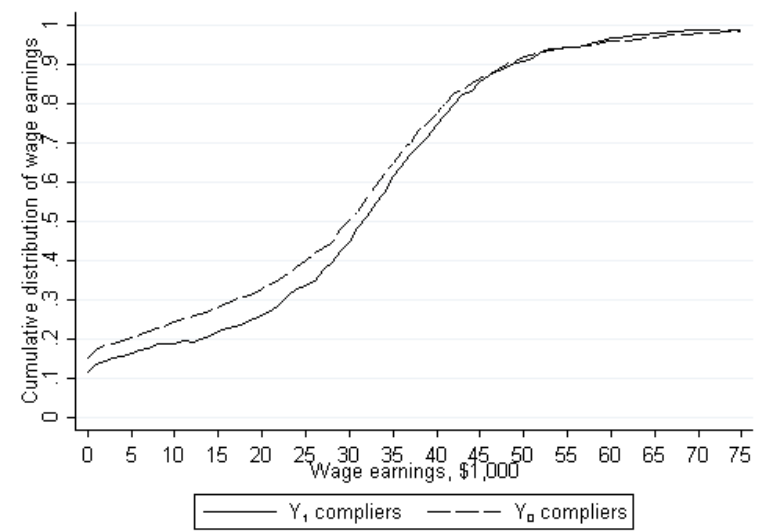

E) Counterfactual cumulated wage earnings distribution, age 9

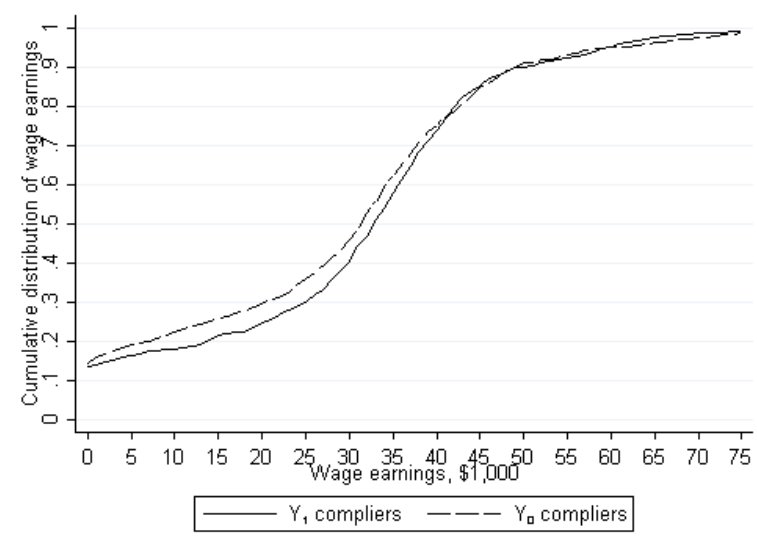

B) Change in density in wage earnings distribution, age 7

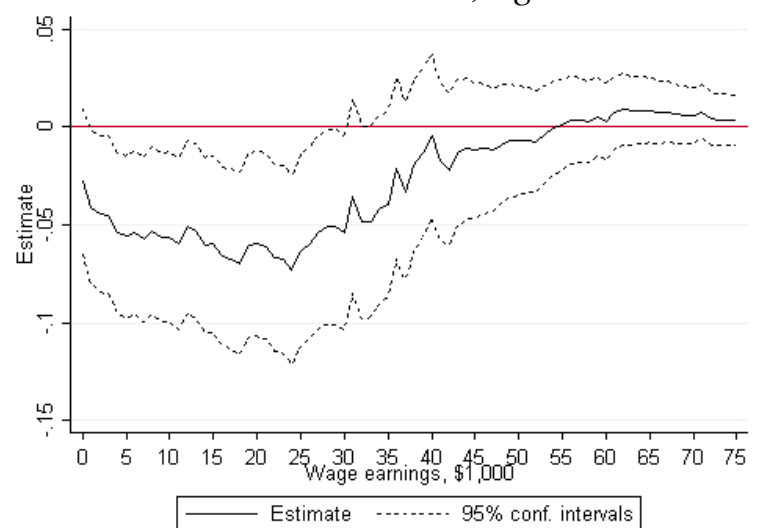

D) Change in density in wage earnings distribution, age 8

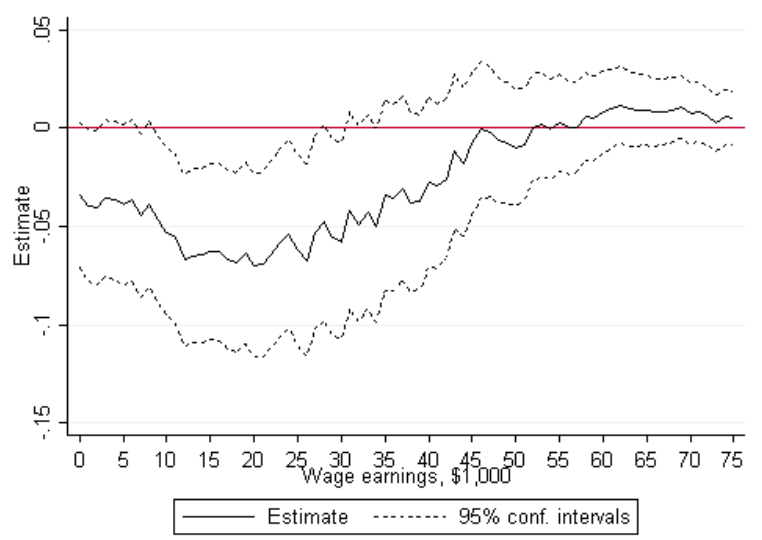

F) Change in density in wage earnings distribution, age 9

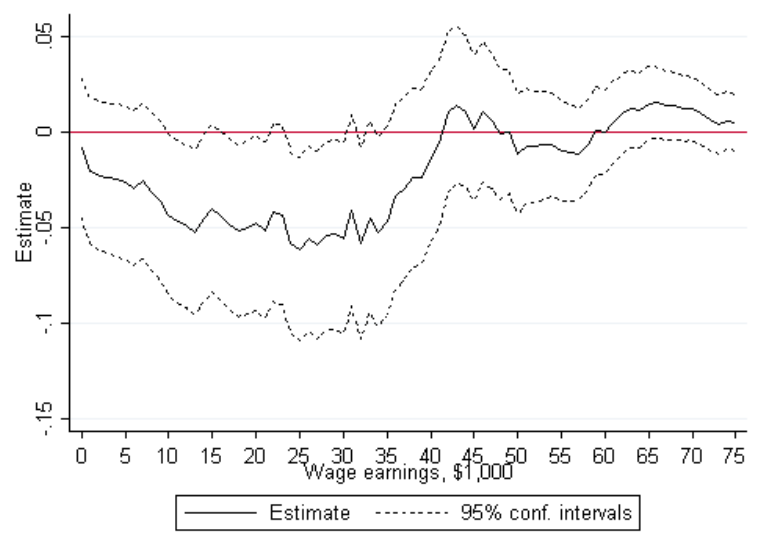

Note: Figures A, C, E show counterfactual cumulated wage earnings distributions of mothers for young-for-grade and old-for-grade children at child's age 7, 8, and 9, respectively. Figures B, D, and F show the changes in densities across income levels induced by old-for-grade relative to being young-for-grade (the vertical differences between the lines in A, $\mathrm{C}$, and $\mathrm{E}$ ). All income levels are on yearly basis. 


\subsection{Effects on siblings}

In Table 4, we present the estimation results for the effects of the focal child's SSA on sibling outcomes. The results confirm the pattern seen above: that a higher SSA seems to ease school experience and release resources in the family. A higher SSA of the focal child does not significantly affect the grades of older siblings who are in lower or middle primary school at the time of the focal child's supposed school start. Yet for siblings who are 7-9 years older than the focal child a higher SSA improves grades substantially. ${ }^{22}$ Note, though, that estimated effects are imprecise and we suggest caution in interpreting the size. These older siblings receive their first teacher assessments and approach graduation at the time when the focal child transitions into elementary school. ${ }^{23}$ An easier school start of the focal child likely improves the performance of the older siblings because the study environment at home is better or because parental resources are freed to assist with homework. In support of this interpretation, only grades in written math and Danish grammar are significantly improved as opposed to grades in essay writing or the oral examination of text analysis. The former disciplines require lower levels of cognition (knowledge, comprehension and application), whereas the latter disciplines require higher levels of cognition (analysis, synthesis, evaluation). ${ }^{24}$ Thus, the former disciplines are more closely related to rote learning and thereby easier to practice, while the latter require verbal creativity and ideational fluency, which are not readily improved in the short run. Interestingly, as shown in Table A5, we see that it is particularly the lower and mid-range grades that are affected by sibling SSA. The probability of receiving a B, C or D in written math and Danish

\footnotetext{
${ }^{22}$ Table A6 in the Appendix reveals some gender heterogeneity in point estimates. For older brothers, point estimates are significantly positive when the age distance is below 3 years. This suggests that some boys may be vulnerable during the first years in school and therefore benefit from younger siblings being old-for-grade.

${ }^{23}$ Table A7 in the Appendix revisits these results using smaller samples that are balanced in terms of the distribution of age distance between siblings across calendar time.

${ }^{24}$ See Bloom (1956).
} 
grammar increases with sibling SSA, while the effect of SSA on receiving an A is close to zero and the probability of receiving an E or F becomes less likely, thereby illustrating that the effects on siblings' grades are indeed concentrated in margins where the road to improved test scores is relatively straightforward.

The effects of SSA on sibling outcomes may also partly run through marital stability or through household income, both of which have been shown to affect children's outcomes (Gruber 2004; Piketty 2003; Dahl and Lochner 2012). If this were the case, we would expect larger effects of SSA on sibling outcomes for children of low educated mothers, because effects on parental outcomes to a high extent are driven by this subgroup (recall Figure A8). Yet, when we investigate effects on siblings' grades by maternal education we find no statistical or qualitative heterogeneity in effects on siblings’ grades.

We interpret our results as suggesting that effects on siblings are not caused by effects on parents' outcomes but rather from the relief of constraints within the families. All families seem to be constrained in terms of investing in their children, while parents with low education face additional constraints in terms of their own outcomes (labor supply, income and marital stability) 
Table 4: Effects of being old-for-grade on older siblings' grades by distance in focal child's and sibling's age

\begin{tabular}{|c|c|c|c|c|}
\hline Age difference & OLS & 2SLS & 2SLS & Observations \\
\hline \multicolumn{5}{|c|}{ Math, standard deviations } \\
\hline $1-3$ years & $\begin{array}{l}-0.107^{* * *} \\
(0.012)\end{array}$ & $\begin{array}{l}0.122 \\
(0.104)\end{array}$ & $\begin{array}{l}0.056 \\
(0.100)\end{array}$ & 31,505 \\
\hline 4-6 years & $\begin{array}{l}-0.128 * * * \\
(0.019)\end{array}$ & $\begin{array}{l}-0.032 \\
(0.183)\end{array}$ & $\begin{array}{l}-0.115 \\
(0.174)\end{array}$ & 14,024 \\
\hline 7-9 years & $\begin{array}{l}-0.132 * * * \\
(0.034)\end{array}$ & $\begin{array}{l}1.065^{* *} \\
(0.392)\end{array}$ & $\begin{array}{l}0.985^{* *} \\
(0.355)\end{array}$ & 4,557 \\
\hline \multicolumn{5}{|c|}{ Danish essay, standard deviations } \\
\hline $1-3$ years & $\begin{array}{l}-0.066^{* * *} \\
(0.012)\end{array}$ & $\begin{array}{l}0.134 \\
(0.104)\end{array}$ & $\begin{array}{l}0.116 \\
(0.098)\end{array}$ & 31,505 \\
\hline 4-6 years & $\begin{array}{l}-0.079 * * * \\
(0.018)\end{array}$ & $\begin{array}{l}0.096 \\
(0.182)\end{array}$ & $\begin{array}{l}0.003 \\
(0.171)\end{array}$ & 14,024 \\
\hline 7-9 years & $\begin{array}{l}-0.119 * * * \\
(0.033)\end{array}$ & $\begin{array}{l}0.037 \\
(0.345)\end{array}$ & $\begin{array}{l}0.101 \\
(0.311)\end{array}$ & 4,557 \\
\hline \multicolumn{5}{|c|}{ Danish grammar, standard deviations } \\
\hline $1-3$ years & $\begin{array}{l}-0.102^{* * *} \\
(0.012)\end{array}$ & $\begin{array}{l}0.106 \\
(0.103)\end{array}$ & $\begin{array}{l}0.079 \\
(0.099)\end{array}$ & 31,505 \\
\hline 4-6 years & $\begin{array}{l}-0.121^{* * *} \\
(0.018)\end{array}$ & $\begin{array}{l}0.279 \\
(0.184)\end{array}$ & $\begin{array}{l}0.189 \\
(0.175)\end{array}$ & 14,024 \\
\hline $7-9$ years & $\begin{array}{l}-0.139 * * * \\
(0.033)\end{array}$ & $\begin{array}{l}0.768^{*} \\
(0.368)\end{array}$ & $\begin{array}{l}0.763^{*} \\
(0.336)\end{array}$ & 4,557 \\
\hline \multicolumn{5}{|c|}{ Danish oral, standard deviations } \\
\hline $1-3$ years & $\begin{array}{l}-0.081^{* * *} \\
(0.012)\end{array}$ & $\begin{array}{l}0.097 \\
(0.103)\end{array}$ & $\begin{array}{l}0.076 \\
(0.099)\end{array}$ & 31,505 \\
\hline 4-6 years & $\begin{array}{l}-0.101^{* * *} \\
(0.019)\end{array}$ & $\begin{array}{l}-0.043 \\
(0.182)\end{array}$ & $\begin{array}{l}-0.123 \\
(0.174)\end{array}$ & 14,024 \\
\hline $7-9$ years & $\begin{array}{l}-0.105^{* *} \\
(0.034)\end{array}$ & $\begin{array}{l}-0.124 \\
(0.342)\end{array}$ & $\begin{array}{l}-0.070 \\
(0.316)\end{array}$ & 4,557 \\
\hline $\begin{array}{l}\text { Distance to cutoff } \\
\text { Covariates }\end{array}$ & $\begin{array}{l}X \\
X\end{array}$ & $\mathrm{X}$ & $\begin{array}{l}X \\
X\end{array}$ & \\
\hline
\end{tabular}

Note: Table shows the estimated effects of being old-for-grade based on OLS and 2SLS regressions of older siblings' grades at the end of grade 9. Cutoff dummy (January $=1$ ) used as instrument. Conditioning set includes distance to cutoff, cohort fixed effects and background characteristics (see Table A1). Standard errors in parentheses $+\mathrm{p}<0.10,{ }^{*} \mathrm{p}<0.05$, ${ }^{* *} \mathrm{p}<0.01,{ }^{* * *} \mathrm{p}<0.001$. 


\subsection{Selection on unobserved variables and external validity}

We next investigate selection on unobserved variables and, within that context, discuss the external validity of our results. We have so far interpreted the results as effects for specific time-constrained families whose choice of SSA is affected by the institutions and policy-environment they face. If this were indeed the case, we would expect our estimated effects of school start age to be local and not generalizable to other types of families who are not constrained in a similar manner.

To test this, we therefore employ the two tests of the conditional independence assumption suggested by Black et al. (2015). We test expected outcomes for never-takers $\left(E\left(\mathrm{Y}_{0} \mid \mathrm{SSA}_{1}=0, \mathrm{SSA}_{0}=0\right)\right)$ and always-takers $\left(\mathrm{E}\left(\mathrm{Y}_{1} \mid \mathrm{SSA}_{1}=1, \mathrm{SSA}_{0}=1\right)\right)$ against the outcomes for compliers and compute "biases," $\mathrm{B}_{0}$ and $\mathrm{B}_{1}$. These measure the difference in expected outcome of never-takers compared to compliers conditional on being young-for-grade $\left(\mathrm{B}_{0}\right)$, and the difference in the expected outcome of compliers compared to always-takers conditional on being old-for-grade $\left(\mathrm{B}_{1}\right)$.

Appendix Figure $A 9$ shows $\mathrm{B}_{0}$ and $\mathrm{B}_{1}$ using parents' marriage/cohabitation rates as outcome. The figure reveals that the relationship stability of compliers’ parents is higher because they are favorably selected compared to always-takers (even borderline significant before school start), whereas there are no differences between non-treated compliers and never-takers. At ages 15-19, in particular, marriage/cohabitation rates of parents to old-for-grade compliers are substantially higher relative to the parents of always-takers, suggesting that the parental response during the years around graduation from compulsory education is a consequence only for certain types of families.

Likewise, Appendix Figure A10 shows $\mathrm{B}_{0}$ and $\mathrm{B}_{1}$ for maternal employment rates. The figure shows that there are not any significant pre-school differences in maternal employment rates, while differences emerge later in the children's life. These differences are statistically significant for always-takers from ages 7-15, while they are rarely significant for never-takers. 
In conclusion, Figures A9 and A10 emphasize that the expected outcomes conditional on treatment for compliers tend to be equal to that observed for never-takers, but not for always-takers. This is because the main component in the school start decision is child maturity, school readiness and behavior in childcare. Among always-taking families, these factors dictate SSA no matter whether the child is born on one or the other side of the cutoff. It is thus reassuring that our analyses show that the family responses to later school start are present for particular types of families, and not readily extrapolated to the population as a whole.

\section{Conclusion}

This paper explores intra-family spillovers from the timing of an important life event, namely the age at which one child in the family starts school. Because the age at school start affects the entire life course, it also naturally impacts the timing of other important educational transitions. Our research design exploits quasi-random shifts in the timing of transitions into (and effectively also away from) school induced by date of birth around an administrative cutoff date.

Our findings reveal that SSA is important for family outcomes for parents and siblings. Parents are more likely to remain together during their child's childhood and adolescence and mothers are more likely to increase their labor supply at both the extensive and intensive margins at the time of school start if the child starts grade 1 at age 7.6 rather than 6.6. Older siblings improve their academic achievement if the focal child is older when they enroll in school. Hence, the key to understanding the increasing average age of school start seen around the Western world may lie in families - not only the individual children. This is because educational institutions, policies and decisions affect not only the child in question but also generate substantial spillover effects and affect important decisions made within the family. 


\section{References}

Abadie, A. (2002), 'Bootstrap Tests for Distributional Treatment Effects in Instrumental Variable Models’ Journal of the American Statistical Association 97(457) pp. 284-292.

Abadie, A. (2003), 'Semiparametric instrumental variable estimation of treatment response models', Journal of Econometrics 113(2), pp. 231-263.

Aliprantis, D. (2012), 'Redshirting, compulsory schooling laws, and educational attainment', Journal of Educational and Behavioral Statistics 37(2), pp. 316-38.

Almlund, M., A. L. Duckworth, J. J. Heckman and T. Kautz (2011), 'Personality Psychology and Economics' Chapter 1 in the Handbook of the Economics of Education 4, pp. 1-181, Elsevier.

Almond, D. and J. J. Doyle (2011), ‘After Midnight: A Regression Discontinuity Design in Length of Postpartum Hospital Stays', American Economic Journal: Economic Policy 3(3), pp. 1-34.

Andersen, S.H. and C. Wildeman (2014), ‘The Effect of Paternal Incarceration on Children’s Risk of Foster Care Placement', Social Forces 93(1), pp. 269-298.

Barua, R. and Lang, K. (2016), 'School Entry, Educational Attainment and Quarter of Birth: A Cautionary Tale of a Local Average Treatment Effect', Journal of Human Capital 10(3), pp. 347376.

Becker, G. S. and Tomes, N. (1976), 'Child Endowments and the Quantity and Quality of Children’, Journal of Political Economy 84, pp. S143-S162.

Becker, G. S. and Tomes, N. (1979), 'An equilibrium theory of the distribution of income and intergenerational mobility', Journal of Political Economy 87, pp. 1153-1189. 
Bedard, K. and Dhuey, E. (2006), 'The persistence of early childhood maturity: international evidence of long-run age effects', Quarterly Journal of Economics 121 (4), pp. 1437-1472.

Black, D. A., J. Joonhwi, R. LaLonde, J. A. Smith and E. J. Taylor (2015), ‘Simple Tests for Selection Bias: Learning More from Instrumental Variables,' IZA DP \#9346.

Black, S. E., S. N. Breining, D. Figlio, J. Guryan, H. S. Nielsen, K. Karbownik, J. Roth, M. Simonsen (2017), Sibling Spillovers, NBER WP \#23062.

Black, S.E., Devereux, P.J. and Salvanes, K.G. (2011), 'Too young to leave the nest? The effects of school starting age', Review of Economics and Statistics 93(2), pp. 455-467.

Blau, F. D. and Kahn, L. M. (2017), 'The Gender Wage Gap: Extent, Trends, and Explanations', Journal of Economic Literature 55(3), pp. 789-865.

Bloom, B. (1956), Taxonomy of educational objectives: The classification of educational goals, 1st ed. England: Longman Group.

Bonke, J. and Fallesen, P. (2010) 'The impact of incentives and interview methods on response quantity and quality in diary- and booklet-based surveys’, Survey Research Methods 4(2), pp. 91-101.

Breining, S. N. (2014), 'The presence of ADHD: Spillovers between siblings', Economics Letters 124, pp. 469-473.

Buckles, K. S. and D. M. Hungerman (2013), 'Season of Birth and Later Outcomes: Old Questions, New Answers‘, Review of Economics and Statistics 95(3), pp. 711-724.

Cascio, E. and Schanzenbach, D. W. (2013), 'The Impacts of Expanding Access to High-Quality Preschool Education', Brookings Papers on Economic Activity, Economic Studies Program 47(2), pp. 127-192. 
Cook, P. J., and Kang S. (2016). 'Birthdays, Schooling, and Crime: Regression-Discontinuity Analysis of School Performance, Delinquency, Dropout, and Crime Initiation.' American Economic Journal: Applied Economics 8(1), pp. 33-57.

Cunha, F. and Heckman, J.J (2007), ‘The technology of skill formation’, American Economic Review 97, pp. 31-47.

Dahl, G. and L. Lochner (2012), 'The Impact of Family Income of Child Achievement: Evidence from the Earned Income Tax Credit’, American Economic Review 102, pp. 1927-1956.

Dee, T. and H. H. Sievertsen (2015), 'The Gift of Time? School Starting Age and Mental Health', NBER WP \# 21610.

Deming, D. and S. Dynarski (2008), 'The Lengthening of Childhood', Journal of Economic Perspectives 22(3), pp. 71-92.

Dhuey, E., D. Figlio, K. Karbownik and J. Roth (2017), 'School Starting Age and Cognitive Development', NBER WP \# 23660.

Dustmann, C., P. Puhani and U. Schönberg (2017), 'The Long-Term Effects of Early Track Choice’, Economic Journal127 1348-1380.

Elder, T.E. (2010), 'The importance of relative standards in ADHD diagnoses: evidence based on exact birth dates', Journal of Health Economics 29(5), pp. 641-656.

Evans, W.N., Morrill, M.S. and Parente, S.T. (2010), 'Measuring excess medical diagnosis and treatment in survey data: the case of ADHD among school-age children', Journal of Health Economics 29(5), pp. 657-673. 
Fiorini, M., and Stevens, K. (2013), 'Assessing the Monotonicity Assumption in IV and fuzzy RD designs’, Working Paper 2013-06, University of Sydney.

Fredriksson, P., and Öckert, B. (2013), 'Life-cycle effects of age at school start', Economic Journal 124(579), pp. 977-1004.

Fredriksson, P., Öckert, B. and H. Oosterbeek (2016), 'Parental Responses to Public Investments in Children: Evidence from a Maximum Class Size Rule’, Journal of Human Resources 51(4), pp. 832868.

Garces, E., Duncan, T., and Currie, J. (2002), 'Longer-Term Effects of Head Start', American Economic Review 92(2), pp. 999-1072.

Gelber, A. and A. Isen (2013), ‘Children’s Schooling and Parents’ Behavior: Evidence from the Head Start Impact Study', Journal of Public Economics 101: 25-38.

Gruber, J., (2004), 'Is Making Divorce Easier Bad for Children? The Long-Run Implications of Unilaterial Divorce', Journal of Labor Economics 22(4), pp. 799-833.

Heckman, J. J. and Y. Rubinstein (2001), “The Importance of Noncognitive Skills: Lessons from the GED Testing Program.” American Economic Review 91(2), pp. 145-149.

Holmes, T. H. and Rahe, R. H. (1967), 'The social readjustment rating scale', Journal of Psychosomatic Research 11, pp. 213-218.

Joensen, J. S. and H. S. Nielsen (2017), 'Spillovers in Educational Choice', Manuscript http://ssrn.com/abstract=2548702.

Kvist, A. P., H. S. Nielsen and M. Simonsen (2013), 'The Importance of Children’s ADHD for Parents’ Relationship Stability and Labor Supply’, Social Science and Medicine 88(July), pp. 30-38. 
Kuziemko, I. (2014), 'Human Capital Spillovers in Families: Do Parents Learn from or Lean on Their Children?', Journal of Labor Economics 32, pp. 755-786.

Landersø, R., H. S. Nielsen and M. Simonsen (2017), 'School Starting Age and the Crime-Age Profile.’ Economic Journal 127: 1096-1118.

Manski, C. F. (1993), 'Identification of endogenous social effects: The reflection problem’, Review of Economic Studies 60(3), pp. 531-542.

Manski, C. F. (2000), 'Economic analysis of social interactions', Journal of Economic Perspectives 14(3), pp. 115-136

Nicoletti C., and Rabe B. (2014), 'Sibling spillover effects on school achievements', ISER Working Paper Series 2014-40, University of Essex

Piketty, T. (2003), ‘The Impact of Divorce on School Performance: Evidence from France, 19682002’, CEPR Discussion Paper no. 4146, London.

Pop-Eleches, C. and Urquiola, M. (2013), 'Going to a Better School: Effects and Behavioral Responses’, American Economic Review 103(4), pp. 1289-1324

Qureshi, J. (forthcoming), ‘Additional Returns to Investing in Girls’ Education: Impact on Younger Sibling Human Capital?’ Forthcoming in Economic Journal.

Skolestartsudvalget (2006), A good school start. A cohesive education including preschool, school and after-school care. (In Danish: En god skolestart. Et samlet læringsforløb for dagtilbud, indskoling og fritidsordning). Report from the Government’s Committee on School Start, Feb 2006.

Yi, J., J. J. Heckman, J. Zhang and G. Conti (2015), 'Early Health Shocks, Intra-Household Resource Allocation and Child Outcomes.' Economic Journal 125, pp. F347-F371. 


\section{Appendix A. Supplementary tables and figures}

Table A1: Summary characteristics

\begin{tabular}{|c|c|c|c|c|c|c|}
\hline & All & $\begin{array}{l}\text { Old-for-grade } \\
=0\end{array}$ & $\begin{array}{l}\text { Old-for-grade } \\
=1\end{array}$ & December & January & Compliers \\
\hline Old-for-grade & $\begin{array}{c}0.725 \\
(0.446)\end{array}$ & $\begin{array}{c}0.000 \\
-\end{array}$ & $\begin{array}{c}1.000 \\
-\end{array}$ & $\begin{array}{c}0.577 \\
(0.494)\end{array}$ & $\begin{array}{c}0.871 \\
(0.335)\end{array}$ & - \\
\hline January $=1$ & $\begin{array}{c}0.504 \\
(0.500)\end{array}$ & $\begin{array}{c}0.236 \\
(0.425)\end{array}$ & $(0.489)$ & $\begin{array}{c}0.000 \\
-\end{array}$ & $\begin{array}{c}1.000 \\
-\end{array}$ & - \\
\hline Boy & $\begin{array}{c}0.510 \\
(0.500)\end{array}$ & $\begin{array}{c}0.349 \\
(0.477)\end{array}$ & $\begin{array}{c}0.571 \\
(0.495)\end{array}$ & $\begin{array}{c}0.510 \\
(0.500)\end{array}$ & $\begin{array}{c}0.510 \\
(0.500)\end{array}$ & $0.379^{\mathrm{A}, \mathrm{C}, \mathrm{D}, \mathrm{E}}$ \\
\hline Birthweight $<2000 \mathrm{~g}$ & $\begin{array}{c}0.042 \\
(0.200)\end{array}$ & $\begin{array}{c}0.031 \\
(0.173)\end{array}$ & $\begin{array}{c}0.046 \\
(0.209)\end{array}$ & $\begin{array}{c}0.043 \\
(0.203)\end{array}$ & $\begin{array}{c}0.040 \\
(0.197)\end{array}$ & $0.056^{\mathrm{B}}$ \\
\hline Mother's age at birth & $\begin{array}{l}28.940 \\
(4.857)\end{array}$ & $\begin{array}{l}29.070 \\
(4.899)\end{array}$ & $\begin{array}{l}28.890 \\
(4.841)\end{array}$ & $\begin{array}{l}28.916 \\
(4.889)\end{array}$ & $\begin{array}{l}28.963 \\
(4.825)\end{array}$ & 28.880 \\
\hline Father's age at birth & $\begin{array}{l}31.598 \\
(5.715)\end{array}$ & $\begin{array}{l}31.835 \\
(5.870)\end{array}$ & $\begin{array}{l}31.510 \\
(5.653)\end{array}$ & $\begin{array}{l}31.570 \\
(5.755)\end{array}$ & $\begin{array}{l}31.626 \\
(5.675)\end{array}$ & 31.765 \\
\hline No siblings & $\begin{array}{c}0.183 \\
(0.387)\end{array}$ & $\begin{array}{c}0.178 \\
(0.383)\end{array}$ & $\begin{array}{c}0.185 \\
(0.388)\end{array}$ & $\begin{array}{c}0.186 \\
(0.389)\end{array}$ & $\begin{array}{c}0.180 \\
(0.384)\end{array}$ & 0.179 \\
\hline 1 sibling & $\begin{array}{c}0.581 \\
(0.493)\end{array}$ & $\begin{array}{c}0.569 \\
(0.495)\end{array}$ & $\begin{array}{c}0.585 \\
(0.493)\end{array}$ & $\begin{array}{c}0.579 \\
(0.494)\end{array}$ & $\begin{array}{c}0.583 \\
(0.493)\end{array}$ & $0.538^{\mathrm{A}, \mathrm{C}, \mathrm{D}, \mathrm{E}}$ \\
\hline 2 siblings & $\begin{array}{c}0.191 \\
(0.393)\end{array}$ & $\begin{array}{c}0.203 \\
(0.402)\end{array}$ & $\begin{array}{c}0.187 \\
(0.390)\end{array}$ & $\begin{array}{c}0.190 \\
(0.392)\end{array}$ & $\begin{array}{c}0.193 \\
(0.395)\end{array}$ & $0.225^{\mathrm{A}, \mathrm{C}, \mathrm{D}, \mathrm{E}}$ \\
\hline 3 siblings & $\begin{array}{c}0.037 \\
(0.188)\end{array}$ & $\begin{array}{c}0.040 \\
(0.196)\end{array}$ & $\begin{array}{c}0.035 \\
(0.184)\end{array}$ & $\begin{array}{c}0.037 \\
(0.188)\end{array}$ & $\begin{array}{c}0.036 \\
(0.187)\end{array}$ & 0.045 \\
\hline 4 or more siblings & $\begin{array}{c}0.008 \\
(0.089)\end{array}$ & $\begin{array}{c}0.009 \\
(0.097)\end{array}$ & $\begin{array}{c}0.007 \\
(0.086)\end{array}$ & $\begin{array}{c}0.008 \\
(0.091)\end{array}$ & $\begin{array}{c}0.008 \\
(0.087)\end{array}$ & 0.013 \\
\hline Parents married/cohab., age 3 & $\begin{array}{c}0.841 \\
(0.366)\end{array}$ & $\begin{array}{c}0.842 \\
(0.364)\end{array}$ & $\begin{array}{c}0.840 \\
(0.367)\end{array}$ & $\begin{array}{c}0.835 \\
(0.371)\end{array}$ & $\begin{array}{c}0.846 \\
(0.361)\end{array}$ & $0.869^{\mathrm{D}}$ \\
\hline Father employed, age 3 & $\begin{array}{c}0.854 \\
(0.353)\end{array}$ & $\begin{array}{c}0.848 \\
(0.359)\end{array}$ & $\begin{array}{c}0.857 \\
(0.351)\end{array}$ & $\begin{array}{c}0.851 \\
(0.356)\end{array}$ & $\begin{array}{c}0.857 \\
(0.350)\end{array}$ & 0.862 \\
\hline Mother employed, age 3 & $\begin{array}{c}0.721 \\
(0.448) \\
\end{array}$ & $\begin{array}{c}0.721 \\
(0.449) \\
\end{array}$ & $\begin{array}{c}0.722 \\
(0.448) \\
\end{array}$ & $\begin{array}{c}0.715 \\
(0.451) \\
\end{array}$ & $\begin{array}{c}0.727 \\
(0.445) \\
\end{array}$ & 0.742 \\
\hline Observations & 132,039 & 36,252 & 95,787 & 65,554 & 66,485 & \\
\hline
\end{tabular}

Note: Table shows results from averages and (standard deviation) for population of children born in December or January from December 1986 to January 2000, by old-for-grade and month of birth. The final column shows average characteristics of the compliers (those whose treatment status is determined by the cutoff) estimated using observations close to the cutoff as $\frac{\pi^{A}+\pi^{C}}{\pi^{A}}\left[E(X \mid D=1, Z=1)-\frac{\pi^{A}}{\pi^{A}+\pi^{C}} E(X \mid D=1, Z=0)\right]$ where $\pi^{A}$ is the fraction of always-takers, $\pi^{N}$ the fraction of never-takers, $\pi^{C}=1-\pi^{A}-\pi^{N}$ is the fraction of compliers (assuming monotonicity), $\mathrm{D}$ is old-forgrade (0/1), and Z is the cutoff (0/1). Standard errors are estimated from 100 bootstraps. Significant differences at a 10\% level: ${ }^{\text {A: }}$ average characteristics of full sample and compliers. ${ }^{\text {B. }}$ average characteristics of children with old-for-grade $=$ 0 and compliers. ${ }^{\text {C: }}$ average characteristics of children with old-for-grade $=1$ and compliers. ${ }^{\text {D: }}$ average characteristics of children born in December and compliers. ${ }^{\mathrm{E}}$ : average characteristics of children born in January and compliers. 
Table A2: Estimation results: Fertility by focal child's and sibling's age

\begin{tabular}{|c|c|c|c|}
\hline Age difference & OLS & 2SLS & 2SLS \\
\hline \multirow[t]{2}{*}{9 years older } & -0.000 & 0.004 & 0.003 \\
\hline & $(0.001)$ & $(0.005)$ & $(0.005)$ \\
\hline \multirow[t]{2}{*}{8 years older } & -0.001 & $-0.012 *$ & $-0.013^{*}$ \\
\hline & $(0.001)$ & $(0.006)$ & $(0.006)$ \\
\hline \multirow[t]{2}{*}{7 years older } & 0.000 & 0.001 & -0.001 \\
\hline & $(0.001)$ & $(0.006)$ & $(0.006)$ \\
\hline \multirow[t]{2}{*}{6 years older } & $-0.002 *$ & 0.002 & 0.000 \\
\hline & $(0.001)$ & $(0.007)$ & $(0.007)$ \\
\hline \multirow[t]{2}{*}{5 years older } & -0.000 & 0.003 & 0.001 \\
\hline & $(0.001)$ & $(0.008)$ & $(0.008)$ \\
\hline \multirow[t]{2}{*}{4 years older } & -0.001 & -0.001 & -0.003 \\
\hline & $(0.001)$ & $(0.009)$ & $(0.009)$ \\
\hline \multirow[t]{2}{*}{3 years older } & -0.002 & -0.010 & -0.011 \\
\hline & $(0.001)$ & $(0.011)$ & $(0.011)$ \\
\hline \multirow[t]{2}{*}{2 years older } & $-0.005^{* *}$ & 0.018 & 0.018 \\
\hline & $(0.001)$ & $(0.012)$ & $(0.012)$ \\
\hline \multirow[t]{2}{*}{1 year older } & $-0.003^{* *}$ & 0.008 & 0.008 \\
\hline & $(0.001)$ & $(0.009)$ & $(0.009)$ \\
\hline \multirow[t]{2}{*}{1 year younger } & 0.000 & -0.015 & -0.014 \\
\hline & $(0.001)$ & $(0.010)$ & $(0.010)$ \\
\hline \multirow[t]{2}{*}{2 years younger } & 0.001 & $-0.022+$ & -0.019 \\
\hline & $(0.002)$ & $(0.013)$ & $(0.013)$ \\
\hline \multirow[t]{2}{*}{3 years younger } & 0.001 & 0.013 & 0.016 \\
\hline & $(0.001)$ & $(0.012)$ & $(0.012)$ \\
\hline \multirow[t]{2}{*}{4 years younger } & $-0.002+$ & 0.003 & 0.005 \\
\hline & $(0.001)$ & $(0.010)$ & $(0.010)$ \\
\hline \multirow[t]{2}{*}{5 years younger } & $-0.003 * *$ & 0.005 & 0.006 \\
\hline & $(0.001)$ & $(0.008)$ & $(0.008)$ \\
\hline \multirow[t]{2}{*}{6 years younger } & -0.000 & 0.010 & 0.011 \\
\hline & $(0.001)$ & $(0.007)$ & $(0.007)$ \\
\hline \multirow[t]{2}{*}{7 years younger } & $-0.001+$ & 0.002 & 0.003 \\
\hline & $(0.001)$ & $(0.006)$ & $(0.006)$ \\
\hline \multirow[t]{2}{*}{8 years younger } & -0.000 & -0.009 & -0.008 \\
\hline & $(0.001)$ & $(0.006)$ & $(0.006)$ \\
\hline \multirow[t]{2}{*}{9 years younger } & -0.000 & -0.001 & -0.000 \\
\hline & $(0.001)$ & $(0.005)$ & $(0.005)$ \\
\hline Distance to cutoff & $X$ & $\mathrm{X}$ & $\mathrm{X}$ \\
\hline Covariates & $\mathrm{X}$ & & $\mathrm{X}$ \\
\hline Observations & 132,039 & 132,039 & 132,039 \\
\hline
\end{tabular}

Note: Table shows the estimated effects of being old-for-grade based on OLS and 2SLS regressions on fertility before and after birth of the focal child. Cutoff dummy (January =1) used as instrument. Conditioning set includes distance to cutoff, cohort fixed effects and background characteristics (see Table A1). Standard errors in parentheses $+\mathrm{p}<0.10,{ }^{*} \mathrm{p}<0.05,{ }^{* *} \mathrm{p}<0.01, * * * \mathrm{p}<0.001$. 
Table A3: Main estimation results on parental outcomes by focal child's age

\begin{tabular}{|c|c|c|c|c|c|}
\hline \multirow[t]{2}{*}{ Age } & \multicolumn{2}{|c|}{ Parents married / cohabiting } & \multicolumn{2}{|c|}{ Maternal employment } & \multirow[t]{2}{*}{ Observations } \\
\hline & OLS & 2SLS & OLS & 2SLS & \\
\hline \multirow[t]{2}{*}{3} & 0.001 & 0.005 & -0.001 & -0.001 & 132039 \\
\hline & $(0.002)$ & $(0.018)$ & $(0.003)$ & $(0.021)$ & \\
\hline \multirow[t]{2}{*}{4} & -0.003 & 0.018 & $0.005+$ & -0.005 & 132039 \\
\hline & $(0.002)$ & $(0.019)$ & $(0.003)$ & $(0.021)$ & \\
\hline \multirow[t]{2}{*}{5} & $-0.007 * *$ & 0.017 & 0.001 & 0.017 & 132039 \\
\hline & $(0.002)$ & $(0.020)$ & $(0.002)$ & $(0.021)$ & \\
\hline \multirow[t]{2}{*}{6} & $-0.011^{* * *}$ & 0.005 & $0.005^{*}$ & 0.005 & 132039 \\
\hline & $(0.002)$ & $(0.021)$ & $(0.002)$ & $(0.021)$ & \\
\hline \multirow[t]{2}{*}{7} & $-0.012 * * *$ & 0.033 & 0.004 & $0.046 *$ & 132039 \\
\hline & $(0.003)$ & $(0.022)$ & $(0.002)$ & $(0.020)$ & \\
\hline \multirow[t]{2}{*}{8} & $-0.011 * * *$ & 0.034 & 0.001 & $0.039+$ & 132039 \\
\hline & $(0.003)$ & $(0.022)$ & $(0.002)$ & $(0.020)$ & \\
\hline \multirow[t]{2}{*}{9} & $-0.011 * * *$ & 0.035 & 0.002 & 0.027 & 132039 \\
\hline & $(0.003)$ & $(0.023)$ & $(0.002)$ & $(0.020)$ & \\
\hline \multirow[t]{2}{*}{10} & $-0.012 * * *$ & 0.035 & $-0.004+$ & 0.023 & 132039 \\
\hline & $(0.003)$ & $(0.024)$ & $(0.002)$ & $(0.020)$ & \\
\hline \multirow[t]{2}{*}{11} & $-0.011 * * *$ & 0.038 & $-0.007 * *$ & 0.021 & 132039 \\
\hline & $(0.003)$ & $(0.024)$ & $(0.002)$ & (0.019) & \\
\hline \multirow[t]{2}{*}{12} & $-0.010 * * *$ & 0.038 & $-0.007 * *$ & $0.033+$ & 132039 \\
\hline & $(0.003)$ & $(0.024)$ & $(0.002)$ & (0.019) & \\
\hline \multirow[t]{2}{*}{13} & $-0.011 * * *$ & 0.037 & $-0.010 * * *$ & 0.021 & 132039 \\
\hline & $(0.003)$ & $(0.025)$ & $(0.002)$ & (0.019) & \\
\hline \multirow[t]{2}{*}{14} & $-0.010 * * *$ & 0.035 & $-0.007 * *$ & 0.012 & 132039 \\
\hline & $(0.003)$ & $(0.025)$ & $(0.002)$ & $(0.019)$ & \\
\hline \multirow[t]{2}{*}{15} & $-0.006^{*}$ & $0.071^{* *}$ & $-0.008 * *$ & 0.026 & 122595 \\
\hline & $(0.003)$ & $(0.026)$ & $(0.002)$ & $(0.020)$ & \\
\hline \multirow[t]{2}{*}{16} & -0.004 & $0.079 * *$ & $-0.006^{* *}$ & 0.021 & 113036 \\
\hline & (0.003) & $(0.027)$ & $(0.002)$ & $(0.021)$ & \\
\hline \multirow[t]{2}{*}{17} & -0.002 & $0.078 * *$ & $-0.007^{*}$ & -0.016 & 103487 \\
\hline & $(0.003)$ & $(0.028)$ & $(0.003)$ & $(0.021)$ & \\
\hline \multirow[t]{2}{*}{18} & -0.002 & $0.067^{*}$ & $-0.006^{*}$ & -0.005 & 93388 \\
\hline & $(0.003)$ & $(0.028)$ & $(0.003)$ & $(0.022)$ & \\
\hline \multirow[t]{2}{*}{19} & -0.001 & $0.061^{*}$ & $-0.007 *$ & -0.002 & 83509 \\
\hline & $(0.004)$ & $(0.029)$ & $(0.003)$ & $(0.023)$ & \\
\hline \multirow[t]{2}{*}{20} & -0.000 & $0.054+$ & $-0.008^{*}$ & -0.012 & 73021 \\
\hline & $(0.004)$ & $(0.031)$ & $(0.003)$ & $(0.025)$ & \\
\hline \multirow[t]{2}{*}{21} & -0.002 & 0.024 & & & 63259 \\
\hline & $(0.004)$ & $(0.033)$ & & & \\
\hline \multirow[t]{2}{*}{22} & -0.002 & 0.028 & & & 53246 \\
\hline & (0.005) & $(0.040)$ & & & \\
\hline Distance to cutoff & & $\mathrm{X}$ & & $\mathrm{X}$ & \\
\hline Covariates & $X$ & $X$ & $\mathrm{X}$ & $\mathrm{X}$ & \\
\hline
\end{tabular}

Note: Table shows the estimation results presented in Figures 5A and 6A along with the corresponding OLS estimates. Standard errors in parentheses $+\mathrm{p}<0.10,{ }^{*} \mathrm{p}<0.05$, ${ }^{* *} \mathrm{p}<0.01,{ }^{* * *} \mathrm{p}<0.001$. 
Table A4: Main estimation results on parental outcomes by focal child's grade level

\begin{tabular}{|c|c|c|c|c|c|}
\hline \multirow[t]{2}{*}{ Grade } & \multicolumn{2}{|c|}{ Parents married / cohabiting } & \multicolumn{2}{|c|}{ Maternal employment } & \multirow[t]{2}{*}{ Observations } \\
\hline & OLS & 2SLS & OLS & 2SLS & \\
\hline 0 & $\begin{array}{c}-0.027^{* * *} \\
(0.002)\end{array}$ & $\begin{array}{c}-0.008 \\
(0.021)\end{array}$ & $\begin{array}{c}0.019 * * * \\
(0.002)\end{array}$ & $\begin{array}{l}0.035+ \\
(0.021)\end{array}$ & 132039 \\
\hline 1 & $\begin{array}{c}-0.029 * * * \\
(0.003)\end{array}$ & $\begin{array}{c}0.006 \\
(0.022)\end{array}$ & $\begin{array}{c}0.018^{* * *} \\
(0.002)\end{array}$ & $\begin{array}{l}0.047^{*} \\
(0.021)\end{array}$ & 132039 \\
\hline 2 & $\begin{array}{c}-0.032 * * * \\
(0.003)\end{array}$ & $\begin{array}{c}0.012 \\
(0.022)\end{array}$ & $\begin{array}{c}0.015^{* * *} \\
(0.002)\end{array}$ & $\begin{array}{c}0.057^{* *} \\
(0.020)\end{array}$ & 132039 \\
\hline 3 & $\begin{array}{c}-0.029 * * * \\
(0.003)\end{array}$ & $\begin{array}{c}0.020 \\
(0.023)\end{array}$ & $\begin{array}{c}0.011^{* * *} \\
(0.002)\end{array}$ & $\begin{array}{l}0.041^{*} \\
(0.020)\end{array}$ & 132039 \\
\hline 4 & $\begin{array}{c}-0.029 * * * \\
(0.003)\end{array}$ & $\begin{array}{c}0.013 \\
(0.023)\end{array}$ & $\begin{array}{c}0.010^{* * *} \\
(0.002)\end{array}$ & $\begin{array}{l}0.045^{*} \\
(0.020)\end{array}$ & 132039 \\
\hline 5 & $\begin{array}{c}-0.028^{* * *} \\
(0.003)\end{array}$ & $\begin{array}{c}0.021 \\
(0.024)\end{array}$ & $\begin{array}{c}0.000 \\
(0.002)\end{array}$ & $\begin{array}{l}0.040^{*} \\
(0.020)\end{array}$ & 132039 \\
\hline 6 & $\begin{array}{c}-0.026^{* * *} \\
(0.003)\end{array}$ & $\begin{array}{c}0.022 \\
(0.024)\end{array}$ & $\begin{array}{l}-0.003 \\
(0.002)\end{array}$ & $\begin{array}{c}0.031 \\
(0.019)\end{array}$ & 132039 \\
\hline 7 & $\begin{array}{c}-0.025^{* * *} \\
(0.003)\end{array}$ & $\begin{array}{c}0.024 \\
(0.024)\end{array}$ & $\begin{array}{c}-0.008^{* * *} \\
(0.002)\end{array}$ & $\begin{array}{c}0.013 \\
(0.019)\end{array}$ & 132039 \\
\hline 8 & $\begin{array}{c}-0.026^{* * *} \\
(0.003)\end{array}$ & $\begin{array}{c}0.023 \\
(0.025)\end{array}$ & $\begin{array}{c}-0.010^{* * *} \\
(0.002)\end{array}$ & $\begin{array}{c}0.017 \\
(0.019)\end{array}$ & 132039 \\
\hline 9 & $\begin{array}{c}-0.022^{* * *} \\
(0.003)\end{array}$ & $\begin{array}{l}0.044+ \\
(0.026)\end{array}$ & $\begin{array}{c}-0.009 * * * \\
(0.002)\end{array}$ & $\begin{array}{c}0.017 \\
(0.020)\end{array}$ & 122595 \\
\hline 10 & $\begin{array}{c}-0.019 * * * \\
(0.003)\end{array}$ & $\begin{array}{l}0.063^{*} \\
(0.027)\end{array}$ & $\begin{array}{c}-0.009 * * * \\
(0.002)\end{array}$ & $\begin{array}{c}0.020 \\
(0.021)\end{array}$ & 113036 \\
\hline 11 & $\begin{array}{c}-0.017 * * * \\
(0.003)\end{array}$ & $\begin{array}{l}0.066^{*} \\
(0.028)\end{array}$ & $\begin{array}{c}-0.011^{* * *} \\
(0.003)\end{array}$ & $\begin{array}{l}-0.007 \\
(0.021)\end{array}$ & 103487 \\
\hline 12 & $\begin{array}{c}-0.015^{* * *} \\
(0.003)\end{array}$ & $\begin{array}{l}0.061^{*} \\
(0.028)\end{array}$ & $\begin{array}{c}-0.009 * * * \\
(0.003)\end{array}$ & $\begin{array}{l}-0.012 \\
(0.022)\end{array}$ & 93388 \\
\hline 13 & $\begin{array}{c}-0.013^{* * *} \\
(0.004)\end{array}$ & $\begin{array}{l}0.057+ \\
(0.029)\end{array}$ & $\begin{array}{c}-0.013 * * * \\
(0.003)\end{array}$ & $\begin{array}{l}-0.015 \\
(0.023)\end{array}$ & 83509 \\
\hline 14 & $\begin{array}{c}-0.011^{* *} \\
(0.004)\end{array}$ & $\begin{array}{c}0.038 \\
(0.031)\end{array}$ & $\begin{array}{c}-0.015^{* * *} \\
(0.003)\end{array}$ & $\begin{array}{l}-0.023 \\
(0.025)\end{array}$ & 73021 \\
\hline 15 & $\begin{array}{c}-0.012 * * \\
(0.004)\end{array}$ & $\begin{array}{c}0.016 \\
(0.033) \\
\end{array}$ & & & 63259 \\
\hline Distance to cutoff & & $\mathrm{X}$ & & $\mathrm{X}$ & \\
\hline Covariates & $\mathrm{X}$ & $\mathrm{X}$ & $\mathrm{X}$ & $\mathrm{X}$ & \\
\hline
\end{tabular}

Note: Table shows the estimation results presented in Figures 5C and 6C along with the corresponding OLS estimates. Standard errors in parentheses $+\mathrm{p}<0.10,{ }^{*} \mathrm{p}<0.05, * * \mathrm{p}<0.01,{ }^{* * *} \mathrm{p}<0.001$. 
Table A5: Probability that older sibling receives a given grade or above, by distance in focal

child's and sibling's age

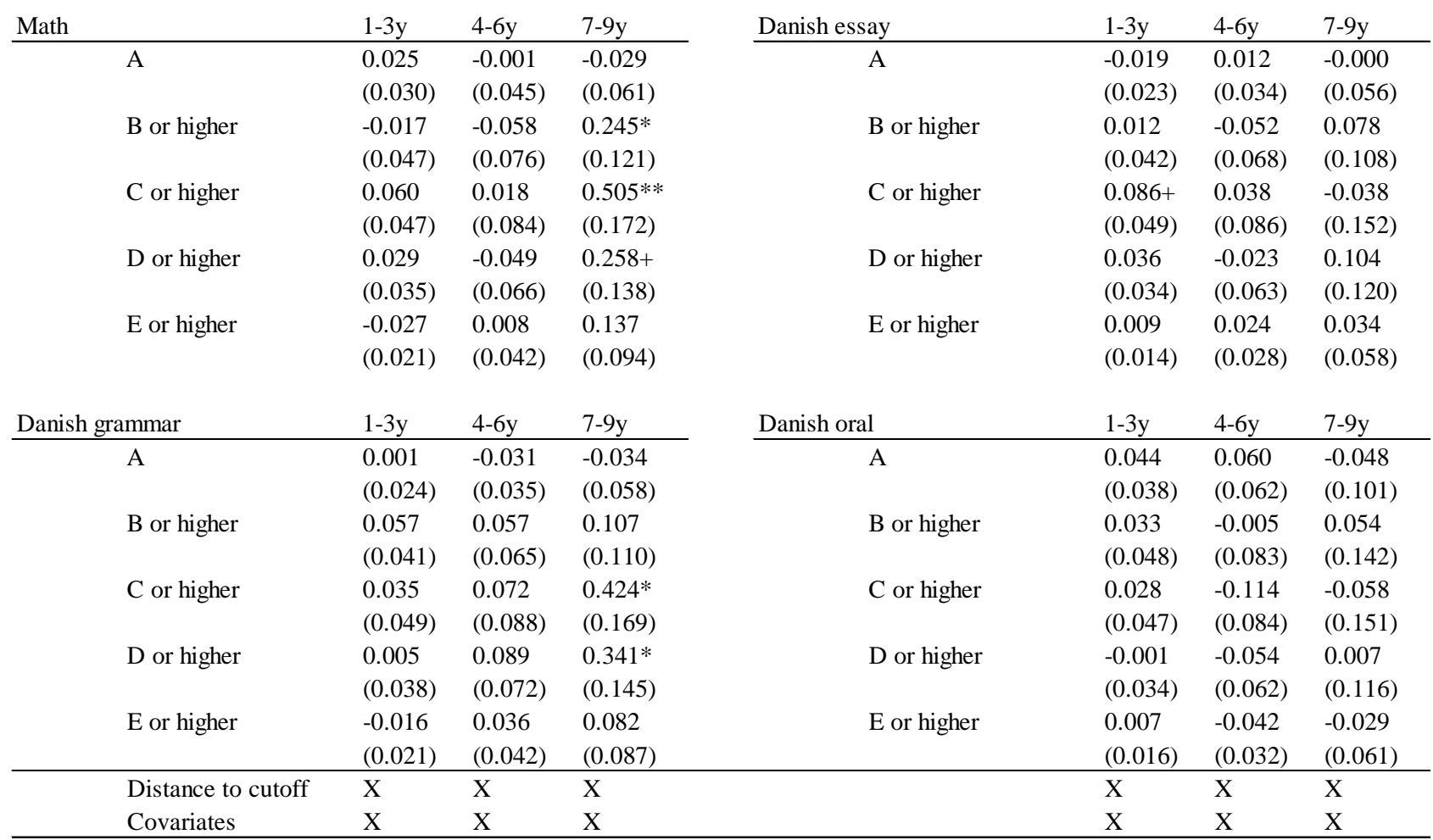

Note: Table shows the estimated effects of being old-for-grade based on 2SLS regressions on the probability that older siblings receive a given grade or higher at the exam at the end of grade 9. Cutoff dummy (January $=1$ ) used as instrument. Conditioning set includes distance to cutoff, cohort fixed effects and background characteristics (see Table A1). Standard errors in parentheses $+\mathrm{p}<0.10,{ }^{*} \mathrm{p}<0.05,{ }^{* *} \mathrm{p}<0.01,{ }^{* * *} \mathrm{p}<0.001$. 
Table A6: Effects of being old-for-grade on older siblings' grades by distance in focal child's and sibling's age and gender

\begin{tabular}{|c|c|c|c|c|c|c|c|c|}
\hline \multirow{2}{*}{ Age difference } & \multicolumn{3}{|c|}{ Older sisters } & \multicolumn{5}{|c|}{ Older brothers } \\
\hline & OLS & 2SLS & 2SLS & Observations & OLS & 2SLS & 2SLS & Observations \\
\hline \multicolumn{9}{|l|}{ Math, standard deviations } \\
\hline $1-3$ years & $\begin{array}{l}-0.107 * * * \\
(0.018)\end{array}$ & $\begin{array}{l}-0.046 \\
(0.148)\end{array}$ & $\begin{array}{l}-0.118 \\
(0.139)\end{array}$ & 15612 & $\begin{array}{l}-0.108 * * * \\
(0.017)\end{array}$ & $\begin{array}{l}0.269+ \\
(0.145)\end{array}$ & $\begin{array}{l}0.236+ \\
(0.143)\end{array}$ & 15893 \\
\hline 4-6 years & $\begin{array}{l}-0.169 * * * \\
(0.027)\end{array}$ & $\begin{array}{l}-0.069 \\
(0.280)\end{array}$ & $\begin{array}{l}-0.257 \\
(0.270)\end{array}$ & 6903 & $\begin{array}{l}-0.089 * * * \\
(0.026)\end{array}$ & $\begin{array}{l}0.018 \\
(0.239)\end{array}$ & $\begin{array}{l}0.006 \\
(0.226)\end{array}$ & 7121 \\
\hline $7-9$ years & $\begin{array}{l}-0.138 * * \\
(0.047)\end{array}$ & $\begin{array}{l}0.598 \\
(0.632)\end{array}$ & $\begin{array}{l}0.707 \\
(0.556)\end{array}$ & 2273 & $\begin{array}{l}-0.128 * * \\
(0.049)\end{array}$ & $\begin{array}{l}1.412 * * \\
(0.503)\end{array}$ & $\begin{array}{l}1.266^{* *} \\
(0.471)\end{array}$ & 2284 \\
\hline \multicolumn{9}{|c|}{ Danish essay, standard deviations } \\
\hline $1-3$ years & $\begin{array}{l}-0.047 * * \\
(0.017)\end{array}$ & $\begin{array}{l}-0.106 \\
(0.140)\end{array}$ & $\begin{array}{l}-0.160 \\
(0.134)\end{array}$ & 15612 & $\begin{array}{l}-0.084 * * * \\
(0.017)\end{array}$ & $\begin{array}{l}0.431^{* *} \\
(0.147)\end{array}$ & $\begin{array}{l}0.400 * * \\
(0.146)\end{array}$ & 15893 \\
\hline 4-6 years & $\begin{array}{l}-0.094 * * * \\
(0.026)\end{array}$ & $\begin{array}{l}0.226 \\
(0.269)\end{array}$ & $\begin{array}{l}0.087 \\
(0.261)\end{array}$ & 6903 & $\begin{array}{l}-0.065^{*} \\
(0.026)\end{array}$ & $\begin{array}{l}-0.056 \\
(0.237)\end{array}$ & $\begin{array}{l}-0.058 \\
(0.227)\end{array}$ & 7121 \\
\hline 7-9 years & $\begin{array}{l}-0.113^{*} \\
(0.046)\end{array}$ & $\begin{array}{l}-0.092 \\
(0.574)\end{array}$ & $\begin{array}{l}0.036 \\
(0.508)\end{array}$ & 2273 & $\begin{array}{l}-0.127 * * \\
(0.047)\end{array}$ & $\begin{array}{l}0.326 \\
(0.412)\end{array}$ & $\begin{array}{l}0.208 \\
(0.396)\end{array}$ & 2284 \\
\hline \multicolumn{9}{|c|}{ Danish grammar, standard deviations } \\
\hline $1-3$ years & $\begin{array}{l}-0.099 * * * \\
(0.017)\end{array}$ & $\begin{array}{l}-0.078 \\
(0.143)\end{array}$ & $\begin{array}{l}-0.138 \\
(0.136)\end{array}$ & 15612 & $\begin{array}{l}-0.104 * * * \\
(0.017)\end{array}$ & $\begin{array}{l}0.330 * \\
(0.146)\end{array}$ & $\begin{array}{l}0.301^{*} \\
(0.145)\end{array}$ & 15893 \\
\hline $4-6$ years & $\begin{array}{l}-0.129 * * * \\
(0.026)\end{array}$ & $\begin{array}{l}0.539+ \\
(0.283)\end{array}$ & $\begin{array}{l}0.386 \\
(0.271)\end{array}$ & 6903 & $\begin{array}{l}-0.114 * * * \\
(0.026)\end{array}$ & $\begin{array}{l}0.031 \\
(0.239)\end{array}$ & $\begin{array}{l}0.012 \\
(0.229)\end{array}$ & 7121 \\
\hline $7-9$ years & $\begin{array}{l}-0.148 * * \\
(0.047)\end{array}$ & $\begin{array}{l}0.961 \\
(0.653)\end{array}$ & $\begin{array}{l}0.956+ \\
(0.573)\end{array}$ & 2273 & $\begin{array}{l}-0.136 * * \\
(0.047)\end{array}$ & $\begin{array}{l}0.801+ \\
(0.439)\end{array}$ & $\begin{array}{l}0.675 \\
(0.417) \\
\end{array}$ & 2284 \\
\hline Distance to cutoff & $\mathrm{X}$ & $\mathrm{X}$ & $\mathrm{X}$ & & $\mathrm{X}$ & $\mathrm{X}$ & $\mathrm{X}$ & \\
\hline Covariates & $\mathrm{X}$ & & $\mathrm{X}$ & & $\mathrm{X}$ & & $\mathrm{X}$ & \\
\hline
\end{tabular}

Note: Table shows the estimated effects of being old-for-grade based on OLS and 2SLS regressions of older siblings' grades at the end of grade 9. Cutoff dummy (January =1) used as instrument. Conditioning set includes distance to cutoff, cohort fixed effects and background characteristics (see Table A1). Standard errors in parentheses $+p<0.10,{ }^{*} p<0.05$, ${ }^{* *} \mathrm{p}<0.01,{ }^{* * *} \mathrm{p}<0.001$ 
Table A7

Estimation results: Older siblings' grades by distance in focal child's and sibling's age

\begin{tabular}{|c|c|c|c|c|c|c|c|c|c|c|c|c|c|}
\hline & Age difference & OLS & 2SLS & 2SLS & Observations & OLS & 2SLS & 2SLS & Observations & OLS & 2SLS & 2SLS & Observations \\
\hline & Sample: & \multicolumn{4}{|c|}{ Max 3 years age distance } & \multicolumn{4}{|c|}{ Max 6 years age distance } & \multicolumn{4}{|c|}{ Max 9 years age distance } \\
\hline \multirow[t]{3}{*}{ Math, standard deviations } & $1-3$ years & $\begin{array}{l}-0.106^{* * *} \\
(0.013)\end{array}$ & $\begin{array}{l}0.130 \\
(0.108)\end{array}$ & $\begin{array}{l}0.068 \\
(0.104)\end{array}$ & 29342 & $\begin{array}{l}-0.115^{* * *} \\
(0.015)\end{array}$ & $\begin{array}{l}0.093 \\
(0.136)\end{array}$ & $\begin{array}{l}0.022 \\
(0.130)\end{array}$ & 21235 & $\begin{array}{l}-0.127^{* * * *} \\
(0.020)\end{array}$ & $\begin{array}{l}0.200 \\
(0.199)\end{array}$ & $\begin{array}{l}0.132 \\
(0.186)\end{array}$ & 12203 \\
\hline & 4-6 years & & & & & $\begin{array}{l}-0.129 * * * \\
(0.020)\end{array}$ & $\begin{array}{l}-0.024 \\
(0.216)\end{array}$ & $\begin{array}{l}-0.126 \\
(0.204)\end{array}$ & 12244 & $\begin{array}{l}-0.140^{* * *} \\
(0.027)\end{array}$ & $\begin{array}{l}0.188 \\
(0.299)\end{array}$ & $\begin{array}{l}0.019 \\
(0.287)\end{array}$ & 7038 \\
\hline & 7-9 years & & & & & & & & & $\begin{array}{l}-0.151^{* * *} \\
(0.039)\end{array}$ & $\begin{array}{l}1.079 * \\
(0.439)\end{array}$ & $\begin{array}{l}1.096 * * \\
(0.416)\end{array}$ & 3556 \\
\hline \multirow[t]{3}{*}{ Danish essay, standard deviations } & $1-3$ years & $\begin{array}{l}-0.067^{* * *} \\
(0.013)\end{array}$ & $\begin{array}{l}0.112 \\
(0.109)\end{array}$ & $\begin{array}{l}0.090 \\
(0.102)\end{array}$ & 29342 & $\begin{array}{l}-0.064^{* * *} \\
(0.015)\end{array}$ & $\begin{array}{l}0.066 \\
(0.137)\end{array}$ & $\begin{array}{l}0.073 \\
(0.128)\end{array}$ & 21235 & $\begin{array}{l}-0.066^{* * *} \\
(0.020)\end{array}$ & $\begin{array}{l}0.148 \\
(0.200)\end{array}$ & $\begin{array}{l}0.196 \\
(0.185)\end{array}$ & 12203 \\
\hline & 4-6 years & & & & & $\begin{array}{l}-0.077^{* * *} \\
(0.020)\end{array}$ & $\begin{array}{l}0.139 \\
(0.217)\end{array}$ & $\begin{array}{l}0.028 \\
(0.201)\end{array}$ & 12244 & $\begin{array}{l}-0.084 * * \\
(0.026)\end{array}$ & $\begin{array}{l}0.053 \\
(0.294)\end{array}$ & $\begin{array}{l}-0.060 \\
(0.280)\end{array}$ & 7038 \\
\hline & 7-9 years & & & & & & & & & $\begin{array}{l}-0.127^{* * * *} \\
(0.037)\end{array}$ & $\begin{array}{l}0.089 \\
(0.384)\end{array}$ & $\begin{array}{l}0.179 \\
(0.358)\end{array}$ & 3556 \\
\hline \multirow[t]{3}{*}{ Danish grammar, standard deviations } & $1-3$ years & $\begin{array}{l}-0.098 * * * \\
(0.013)\end{array}$ & $\begin{array}{l}0.054 \\
(0.108)\end{array}$ & $\begin{array}{l}0.025 \\
(0.103)\end{array}$ & 29342 & $\begin{array}{l}-0.101 * * * \\
(0.015)\end{array}$ & $\begin{array}{l}0.015 \\
(0.136)\end{array}$ & $\begin{array}{l}0.006 \\
(0.129)\end{array}$ & 21235 & $\begin{array}{l}-0.109 * * * \\
(0.020)\end{array}$ & $\begin{array}{l}0.144 \\
(0.198)\end{array}$ & $\begin{array}{l}0.165 \\
(0.185)\end{array}$ & 12203 \\
\hline & 4-6 years & & & & & $\begin{array}{l}-0.115^{* * *} \\
(0.020)\end{array}$ & $\begin{array}{l}0.293 \\
(0.218)\end{array}$ & $\begin{array}{l}0.183 \\
(0.205)\end{array}$ & 12244 & $\begin{array}{l}-0.126 * * * \\
(0.026)\end{array}$ & $\begin{array}{l}0.356 \\
(0.300)\end{array}$ & $\begin{array}{l}0.233 \\
(0.287)\end{array}$ & 7038 \\
\hline & 7-9 years & & & & & & & & & $\begin{array}{l}-0.138^{* * * *} \\
(0.038)\end{array}$ & $\begin{array}{l}0.588 \\
(0.405)\end{array}$ & $\begin{array}{l}0.641+ \\
(0.383)\end{array}$ & 3556 \\
\hline \multirow[t]{3}{*}{ Danish oral, standard deviations } & $1-3$ years & $\begin{array}{l}-0.081^{* * *} \\
(0.012)\end{array}$ & $\begin{array}{l}0.097 \\
(0.103)\end{array}$ & $\begin{array}{l}0.076 \\
(0.099)\end{array}$ & 29342 & $\begin{array}{l}-0.082 * * * \\
(0.015)\end{array}$ & $\begin{array}{l}0.094 \\
(0.137)\end{array}$ & $\begin{array}{l}0.094 \\
(0.130)\end{array}$ & 21235 & $\begin{array}{l}-0.094^{* * * *} \\
(0.020)\end{array}$ & $\begin{array}{l}0.123 \\
(0.198)\end{array}$ & $\begin{array}{l}0.159 \\
(0.185)\end{array}$ & 12203 \\
\hline & 4-6 years & & & & & $\begin{array}{l}-0.098 * * * \\
(0.020)\end{array}$ & $\begin{array}{l}-0.018 \\
(0.215)\end{array}$ & $\begin{array}{l}-0.115 \\
(0.204)\end{array}$ & 12244 & $\begin{array}{l}-0.085^{* *} \\
(0.027)\end{array}$ & $\begin{array}{l}-0.160 \\
(0.295)\end{array}$ & $\begin{array}{l}-0.265 \\
(0.286)\end{array}$ & 7038 \\
\hline & 7-9 years & & & & & & & & & $\begin{array}{l}-0.108^{* *} \\
(0.038)\end{array}$ & $\begin{array}{l}0.056 \\
(0.382)\end{array}$ & $\begin{array}{l}0.120 \\
(0.365)\end{array}$ & 3556 \\
\hline \multicolumn{2}{|l|}{ Focal child cohorts } & \multicolumn{3}{|c|}{ 1990/91-1999/00 } & & \multicolumn{3}{|c|}{ 1993/94-1999/00 } & & \multicolumn{3}{|c|}{ 1996/97-1999/00 } & \\
\hline Distance to cutoff & & $\mathrm{X}$ & $\mathrm{X}$ & $X$ & & $\mathrm{X}$ & $\mathrm{X}$ & $X$ & & $\mathrm{X}$ & $\mathrm{X}$ & $\mathrm{X}$ & \\
\hline Covariates & & $\mathrm{X}$ & & $\mathrm{X}$ & & $\mathrm{X}$ & & $\mathrm{X}$ & & $\mathrm{X}$ & & $\mathrm{X}$ & \\
\hline
\end{tabular}

Note: Table shows the estimated effects of being old-for-grade based on OLS and 2SLS regressions on older siblings' grades at the end of $9^{\text {th }}$ grade. Cutoff dummy (January $=1$ ) used as instrument. Conditioning set includes distance to cutoff, cohort fixed effects and background characteristics (see Table A1). Standard errors in parentheses

$+\mathrm{p}<0.10,{ }^{*} \mathrm{p}<0.05,{ }^{* *} \mathrm{p}<0.01, * * * \mathrm{p}<0.001$ 


\section{Figure A1: Fraction punctual, early and late school start}

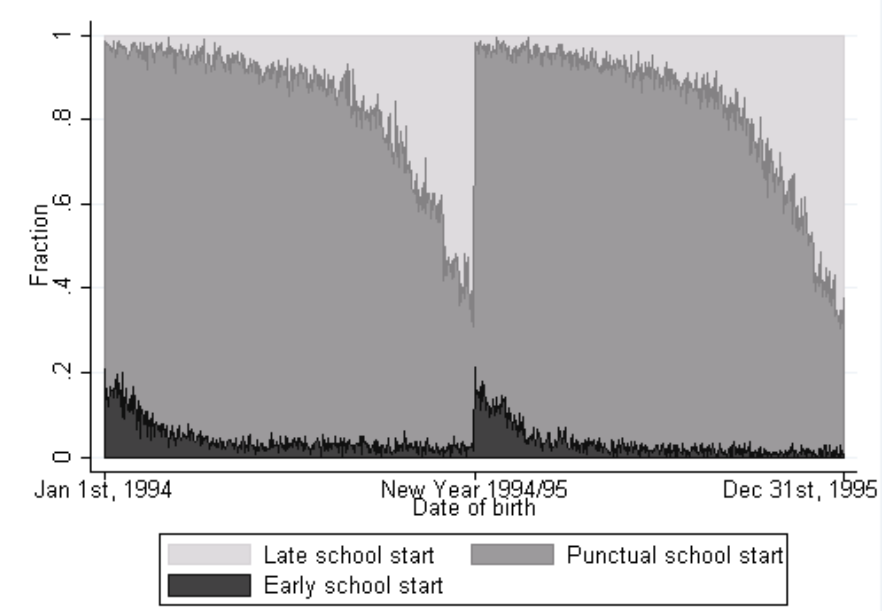

Note: Figure shows the school starting pattern of the full population of children born between January 11994 and January 1 1995. "Early school start" refers to school start the calendar year the child turns 6, "punctual school start" refers to school start the calendar year the child turns 7, and "late school start" refers to school start the calendar year the child turns 8 .

\section{Figure A2: Distribution of distance in time between age of focal child and older sibling}

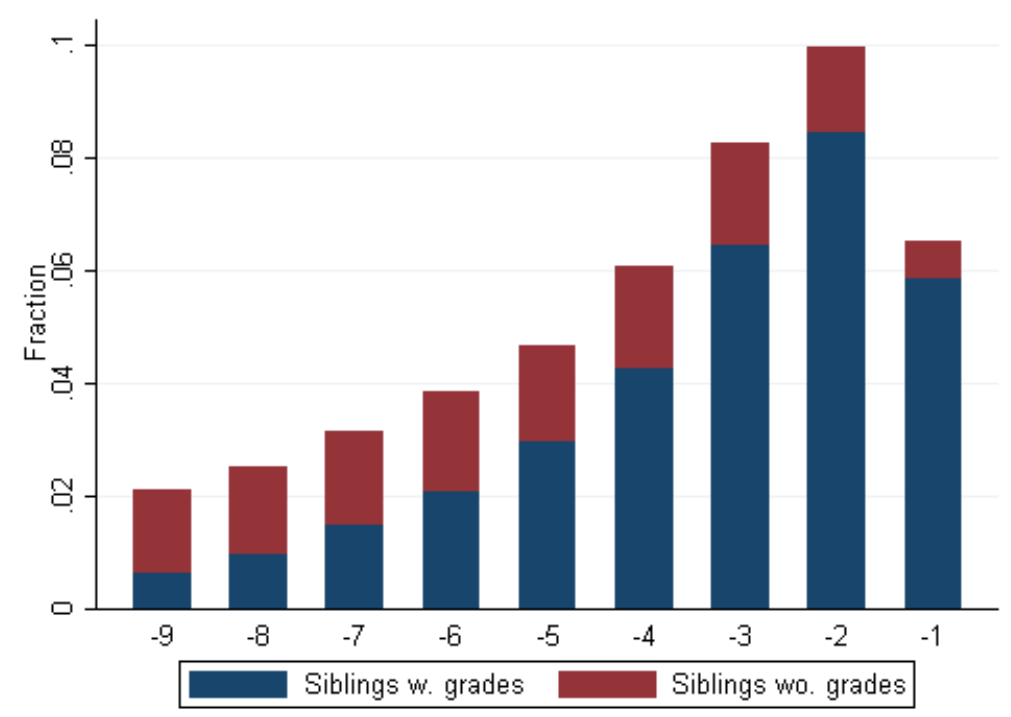

Note: Figure shows histogram of focal child's age minus siblings' age in the sample of children born in December 19861999 and January 1987-2000. The figure indicates the fraction of siblings for whom we have support for grades for older siblings (grades are available from 2002-2014). 


\section{Figure A3: Reduced form: Parents married or cohabiting at child age 15}

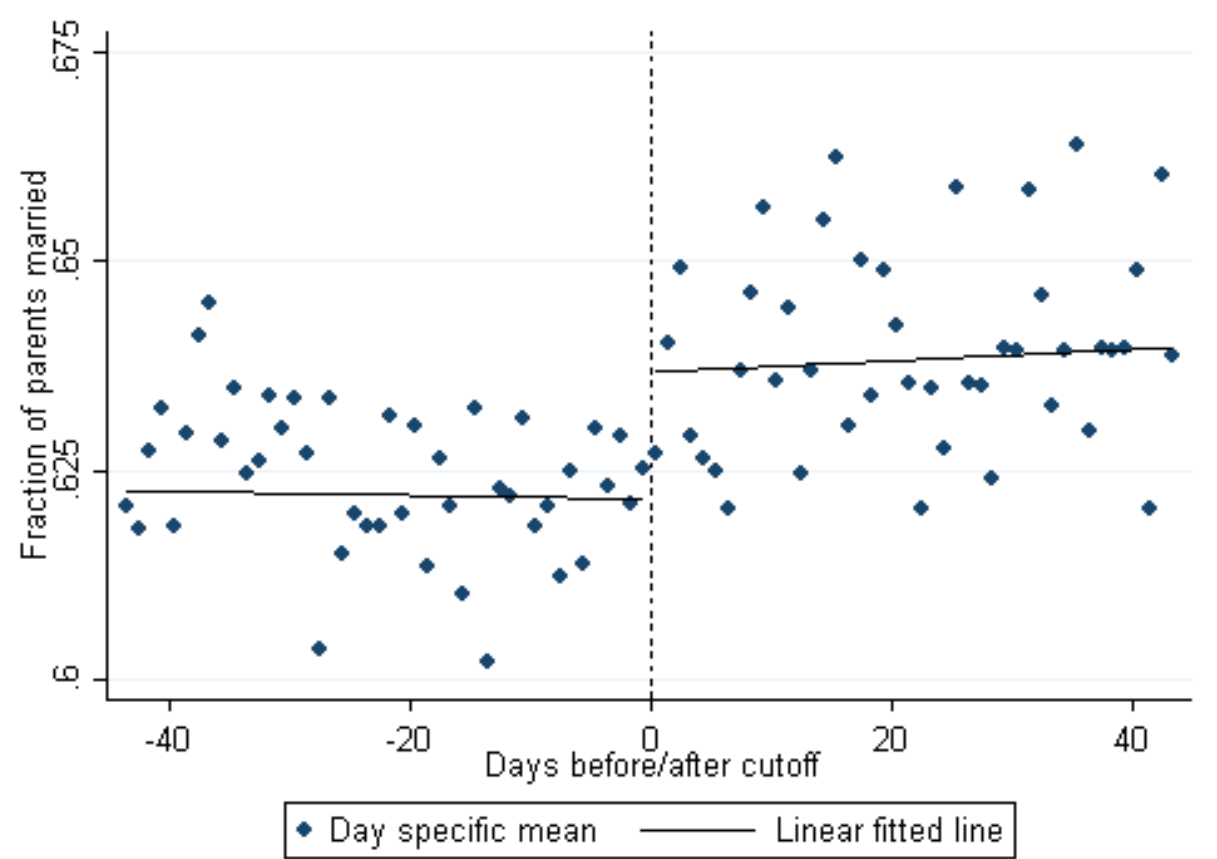

Note: Figure shows the fraction of parents married or cohabiting at child age 15 by date of birth around New Year (marked by the vertical line).

Figure A4: Reduced form: Mother employed at child age 7

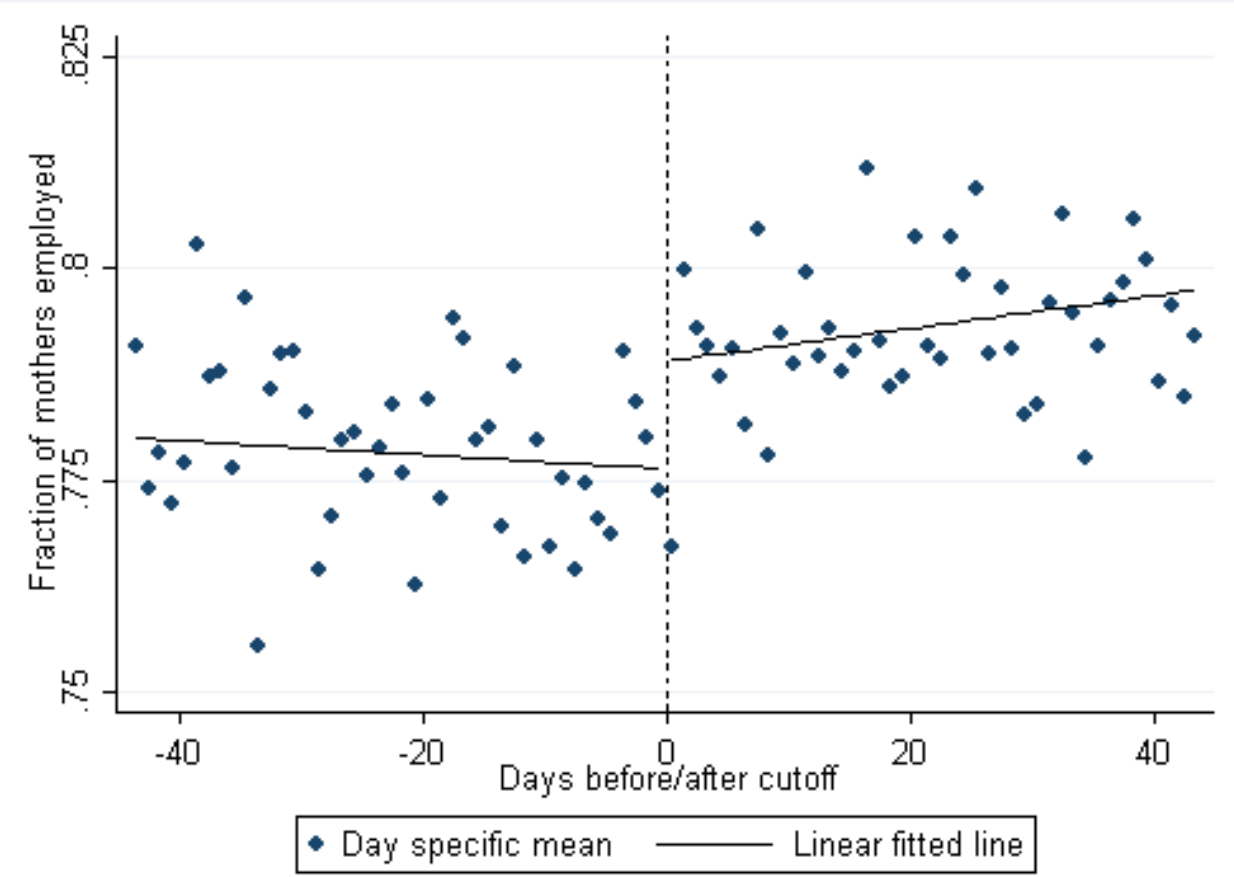

Note: Figure shows the fraction of mothers employed at child age 7 by date of birth around New Year (marked by the vertical line). 


\section{Figure A5: Estimation results with extended bandwidth: Fraction married or cohabiting by}

\section{focal child age}

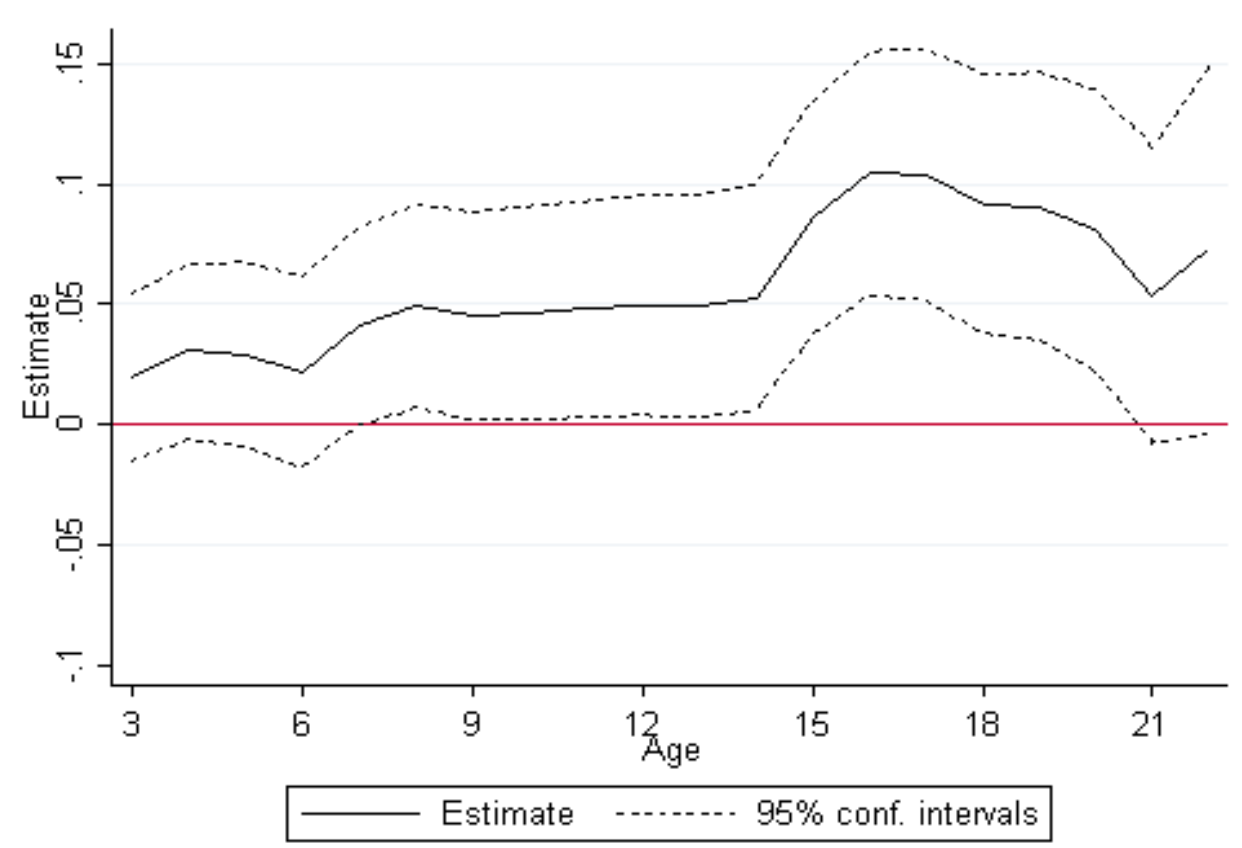

Note: Figure shows the estimated effects of being old-for-grade based on 2SLS regressions of fraction of parents who are married or cohabiting at a given child age. Cutoff dummy (January $=1$ ) used as instrument. Conditioning set includes distance to cutoff, cohort fixed effects and background characteristics (see Table A1). Dashed lines indicate 95\% confidence interval. Bandwidth \pm 45 days. 
Figure A6: Estimation results with extended bandwidth: Employment of mother by focal child age

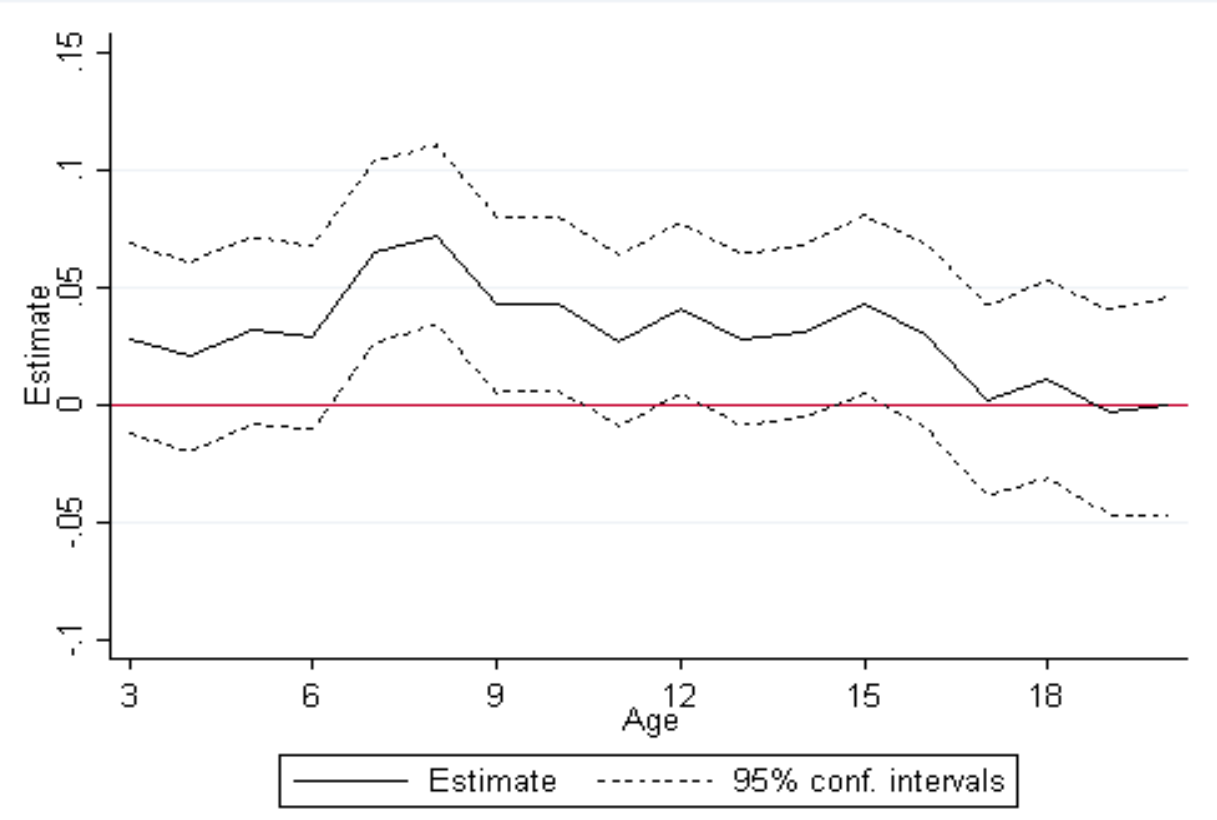

Note: Figure shows the estimated effects of being old-for-grade based on 2SLS regressions of mother's employment at a given child age. Cutoff dummy (January $=1$ ) used as instrument. Conditioning set includes distance to cutoff, cohort fixed effects and background characteristics (see Table A1). Dashed lines indicate 95\% confidence interval. Bandwidth \pm 45 days. 


\section{Figure A7: Estimation results: Mothers' labor earnings percentile by focal child age}

A) Average labor earnings percentile

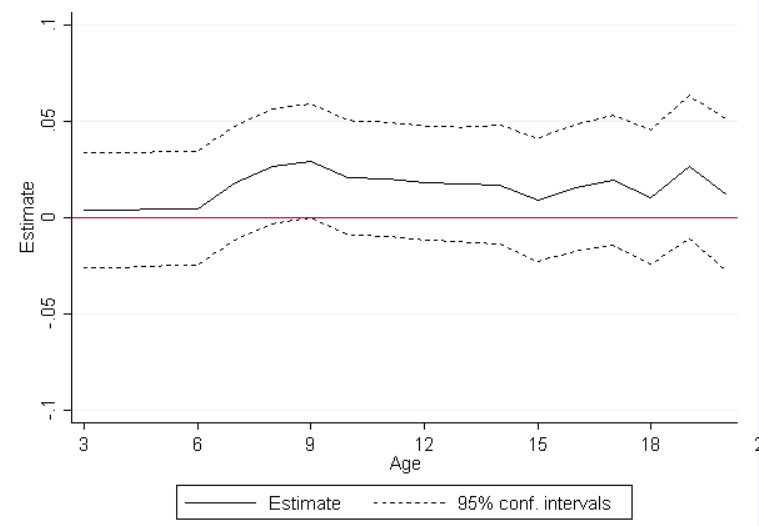

B) Probability of being above the lowest quartile

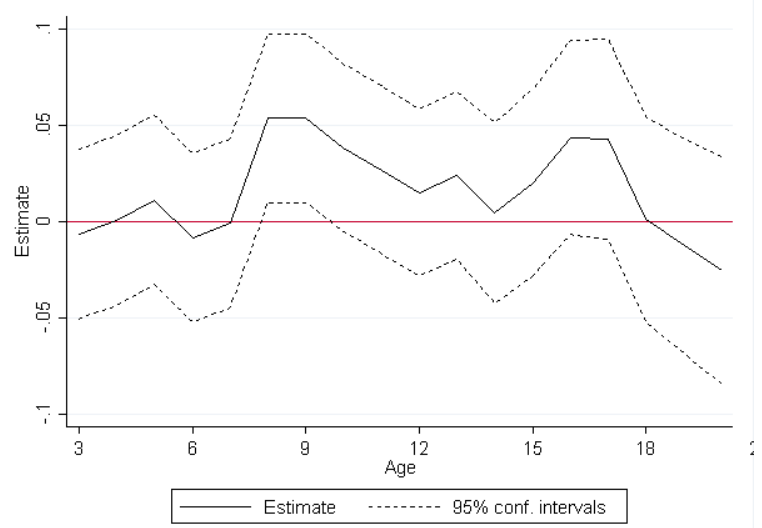

Note: Figure shows the estimated effects of being old-for-grade based on 2SLS regressions on A) mothers' labor earnings percentile (in the female labor earnings distribution) and B) the probability that mothers' do not fall in the lowest quartile of the distribution at a given age. Cutoff dummy (January $=1$ ) used as instrument. Conditioning set includes distance to cutoff, cohort fixed effects and background characteristics (see Table A1). Dashed lines indicate 95\% confidence intervals.

Figure A8: Effects of being old-for-grade on parents' relationship status and mothers' labor employment rates, mothers with high school degree or lower as highest education, by focal child age

A) Fraction married or cohabiting

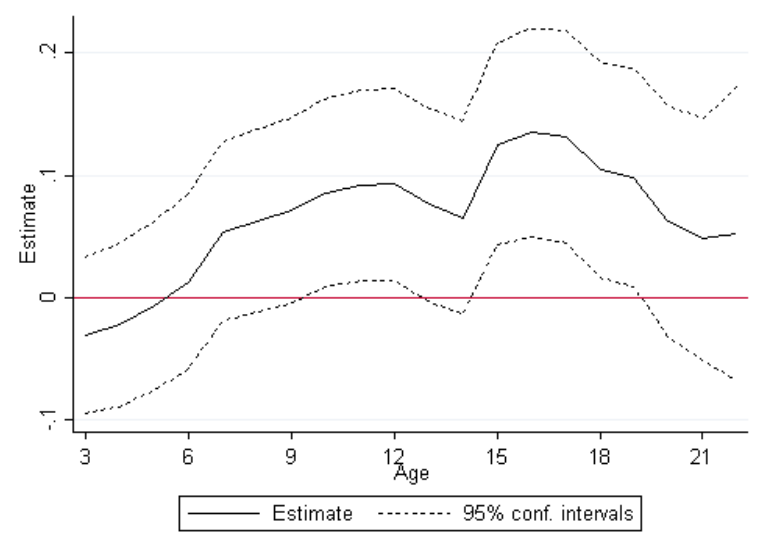

B) Maternal employment rates

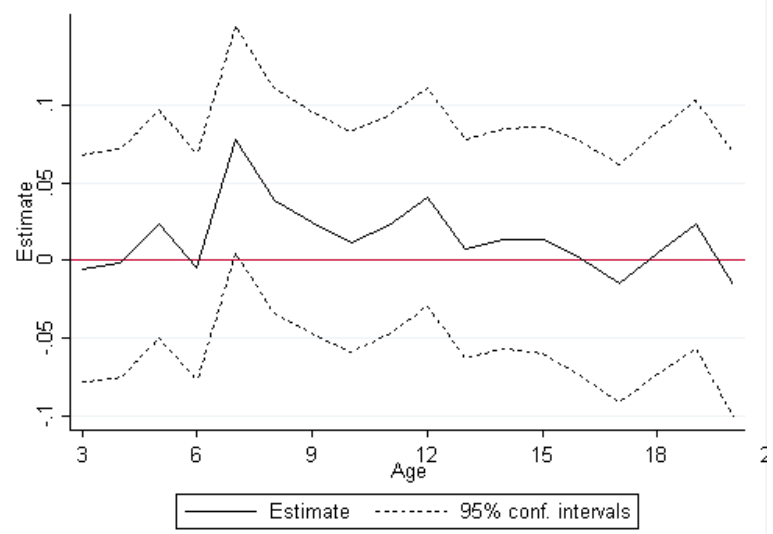

Note: Figure shows the estimated effects of being old-for-grade based on 2SLS regressions on A) probability that parents are married or cohabiting and B) mother's employment at a given child age for mothers with 12 years of completed schooling or less. Cutoff dummy (January =1) used as instrument. Conditioning set includes distance to cutoff, cohort fixed effects and background characteristics (see Table A1). Dashed lines indicate 95\% confidence intervals. 
Figure A9: Selection bias as measured for the outcome parents married or cohabiting

$B_{0}$ (never-takers compared to compliers) $\quad B_{1}$ (compliers compared to always-takers)
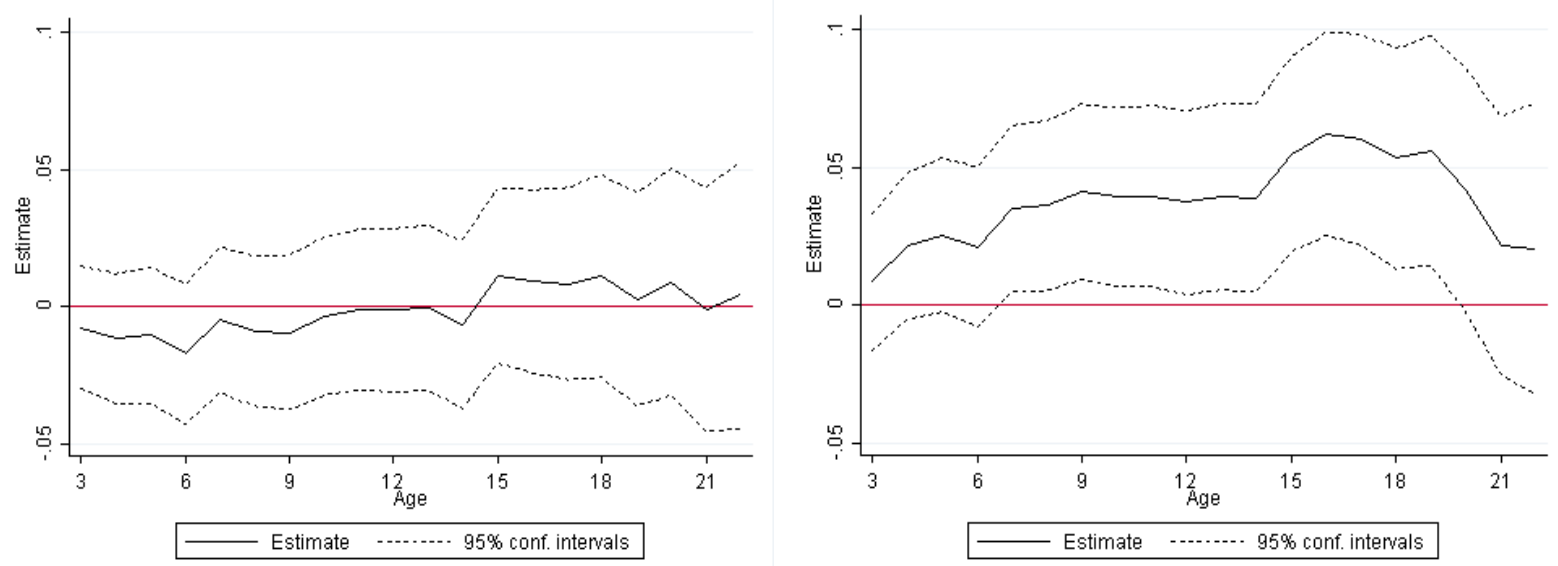

Note: Figure shows test for the conditional independence assumption ATET (left) and ATEN (right).

Figure A10: Selection bias as measured for the outcome maternal employment rates

$B_{0}$ (never-takers compared to compliers) $\quad B_{1}$ (compliers compared to always-takers)
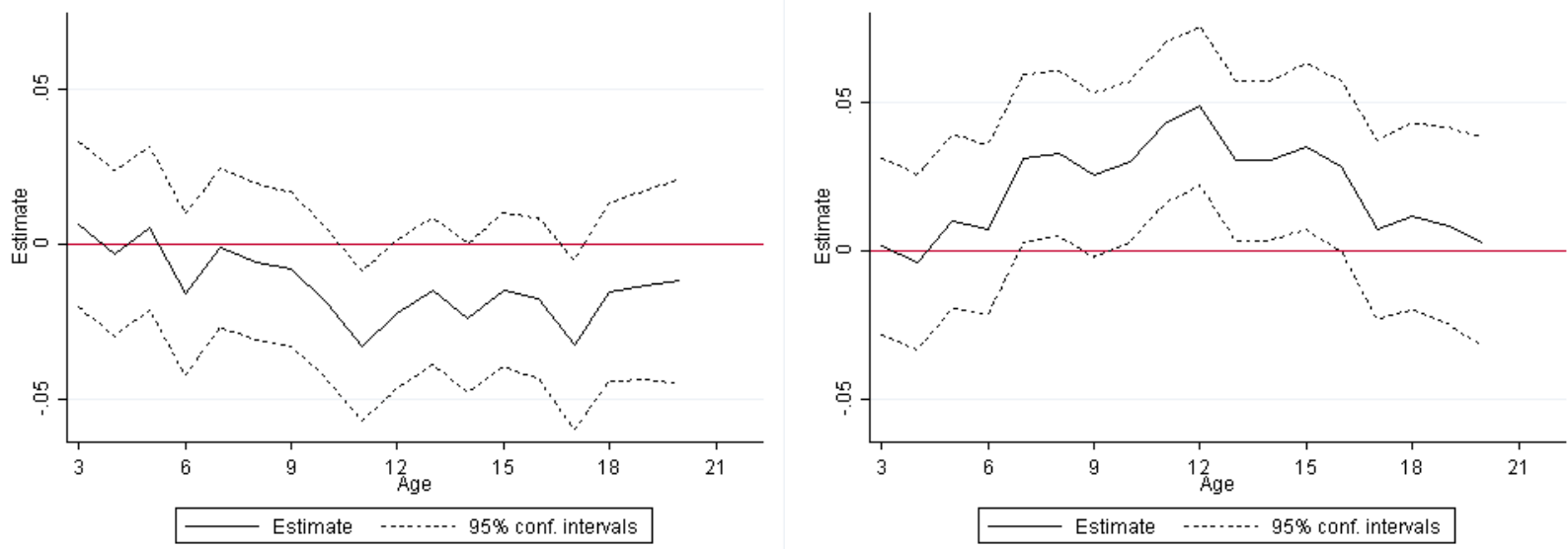

Note: Figure shows test for the conditional independence assumption ATET (left) and ATEN (right). 


\section{Economics Working Papers}

2015-26: Benjamin Friedrich: Trade Shocks, Firm Hierarchies and Wage Inequality

2015-27: Kenneth Lykke Sørensen: Active Labor Market Programs and Reservation Wages: Its a Hazard

2016-01: $\quad$ Alexander K. Koch and Julia Nafziger: Correlates of Narrow Bracketing

2016-02: John Kennes and Daniel le Maire: Competing Auctions of Skills

2016-03: Mette Trier Damgaard and Christina Gravert: The hidden costs of nudging: Experimental evidence from reminders in fundraising

2016-04: Sylvanus Kwaku Afesorgbor and Renuka Mahadevan: The Impact of Economic Sanctions on Income Inequality of Target States

2016-05: Martin Paldam and Erich Gundlach: Jumps into democracy: The transition in the Polity Index

2016-06: Erich Gundlach and Martin Paldam: Socioeconomic transitions as common dynamic processes

2016-07: Rune V. Lesner: Testing for Statistical Discrimination based on Gender

2016-08: $\quad$ Rune V. Lesner: The Long-Term Effect of Childhood Poverty

2016-09: $\quad$ Sylvanus Kwaku Afesorgbor: Economic Diplomacy in Africa: The Impact of Regional Integration versus Bilateral Diplomacy on Bilateral Trade

2016-10: John Kennes and Daniel le Maire: On the equivalence of buyer and seller proposals within canonical matching and pricing environments

2016-11: Ritwik Banerjee, Nabanita Datta Gupta and Marie Claire Villeval: The Spillover Effects of Affirmative Action on Competitiveness and Unethical Behavior

2017-01: Rasmus Landersø, Helena Skyt Nielsen and Marianne Simonsen: How Going to School Affects the Family 